\title{
Smart Solar-Metal-Air Batteries Based on BiOCl Photocorrosion for Monolithic Solar Energy Conversion and Storage
}

Tianyi Ma ( $\nabla$ tianyima@swin.edu.au)

Swinburne University of Technology https://orcid.org/0000-0002-1042-8700

Yalin Lan

Liaoning University

Munkhbayar Batmunkh

Griffith University

Peng Li

Swinburne University of Technology

Bingzhi Qian

Liaoning University

Degang Bu

Liaoning University

Qin Zhao

Liaoning University

Hongwei Huang

China University of Geosciences Bejing

Wenping Sun

Zhejiang University

Yu Zhang

Liaoning University

Xi-Ming Song

Liaoning University

Baohua Jia

Swinburne University of Technology https://orcid.org/0000-0002-6703-477X

Article

Keywords: photocorrosion, hydrogel film electrode, solar cell, metal-air battery, BiOCl

Posted Date: August 3rd, 2021

DOl: https://doi.org/10.21203/rs.3.rs-689298/v1 
License: (c) (i) This work is licensed under a Creative Commons Attribution 4.0 International License. Read Full License 


\title{
Smart Solar-Metal-Air Batteries Based on BiOCl Photocorrosion for Monolithic Solar Energy Conversion and Storage
}

Yalin Lan, ${ }^{\mathrm{a}, \dagger}$ Munkhbayar Batmunkh, ${ }^{\mathrm{b}, \dagger}$ Peng Li, ${ }^{\mathrm{c}}$ Bingzhi Qian, ${ }^{\mathrm{a}}$ Degang Bu, ${ }^{\mathrm{a}}$ Qin Zhao, ${ }^{\mathrm{a}}$ Hongwei Huang, ${ }^{\mathrm{d}}$ Wenping Sun, ${ }^{\mathrm{e}}$ Yu Zhang, ${ }^{\mathrm{a}, *}$ Tianyi Ma, ${ }^{\mathrm{c}, *}$ Xi-Ming Song ${ }^{\mathrm{a}, *}$, Baohua Jia ${ }^{\mathrm{c}, *}$

${ }^{a}$ Liaoning Key Laboratory for Green Synthesis and Preparative Chemistry of Advanced Materials, College of Chemistry, Liaoning University, Shenyang 110036, China

${ }^{b}$ Centre for Catalysis and Clean Energy, School of Environment and Science, Griffith University, Gold Coast, QLD 4222, Australia

${ }^{c}$ Centre for Translational Atomaterials, Swinburne University of Technology, Hawthorn, VIC 3122, Australia

${ }^{d}$ School of Materials Science and Technology, China University of Geosciences, Beijing 100083, China

e School of Materials Science and Engineering, State Key Laboratory of Clean Energy Utilization, Zhejiang University, Hangzhou, 310027, P. R. China.

${ }^{\dagger}$ These authors contributed equally to the work.

*Corresponding authors. E-mail: zhangy@lnu.edu.cn (Yu Zhang); tianyima@swin.edu.au (Tianyi Ma); songlab@lnu.edu.cn (Xi-Ming Song); bjia@swin.edu.au (Baohua Jia)

\begin{abstract}
Solar energy generation and storage are two distinct processes and integrating them in a single device is of great challenge. Herein, $\mathrm{BiOCl}$ hydrogel film electrode featuring excellent photocorrosion and regeneration properties acts as the anode to construct a novel type of smart Solar-Metal-Air Batteries (SMABs), which combine the characteristics of solar cell (direct photovoltaic conversion) and metal-air battery (electric energy storage and release interacting with atmosphere). The cyclic photocorrosion processes between $\mathrm{BiOCl}\left(\mathrm{Bi}^{3+}\right)$ and Bi can simply be achieved by solar light illuminating and standing in dark, corresponding to the charging and discharging processes of the battery, respectively. Upon illumination, the device takes open-circuit configuration to charge itself from the sunlight. Photogenerated electrons in the conduction band of $\mathrm{BiOCl}$ reduce $\mathrm{Bi}^{3+}$ to $\mathrm{Bi}^{0}$ following the photocorrosion
\end{abstract}


process of $\mathrm{BiOCl}$; and in the meantime, photogenerated positive charges (holes) initiate the oxygen evolution reaction to produce $\mathrm{O}_{2}$. Notably, in this system, the converted solar energy can be stored in the SMABs without the need of external batteries to store the electricity like those for the traditional solar cells. In the discharging process in the dark, $\mathrm{Bi}^{0}$ spontaneously turns back to $\mathrm{Bi}^{3+}$ producing electrons to induce oxygen reduction reaction occurring at the counter electrode $(\mathrm{Pt} / \mathrm{C})$ like metal-air battery. With an illumination of $15 \mathrm{~min}$, the battery with an electrode area of $1 \mathrm{~cm}^{2}$ can be continuously discharged for approximately 3,000 s, demonstrating a theoretical capacity of $384.75 \mathrm{mAh} \cdot \mathrm{g}^{-1}$, which is higher than the theoretical capacity of lithium-ion batteries $\left(\mathrm{LiCoO}_{2}, 274 \mathrm{mAh} \cdot \mathrm{g}^{-1}\right)$. This novel type of SMABs is developed for the first time based on the unique photocorrosive and self-oxidation reaction of $\mathrm{BiOCl}$ to achieve photochemical energy generation and storage. The revealed fundamental mechanism and proposed device design create new solutions to the renewable energy harvesting and storage field. This class of solar light direct-charging battery is an effective step to fulfill the need for green and sustainable energy developments and exhibits great promise for the commercial market.

Keywords: photocorrosion, hydrogel film electrode, solar cell, metal-air battery, $\mathrm{BiOCl}$ 


\section{Introduction}

Harvesting energy directly from solar energy using photovoltaic (PV) system is an ultimate solution to the ever-increasing global energy demand. ${ }^{[1-2]}$ Two representative clean energy devices, namely solar cells and metal-air batteries, have drawn a great deal of attention as they promise to be the next-generation energy technologies. Intrinsically, conventional solar cells are instant photoelectric conversion devices; and the generated electric energy needs to be consumed immediately or to be stored via rechargeable batteries for later use. ${ }^{[3]}$ For metal-air batteries, the large overpotential induced by sluggish reaction kinetics and insoluble discharge products usually lead to unsatisfactory battery performance. ${ }^{[4]}$ Excellent efforts have been devoted to utilize photo-assisted techniques in metal-air batteries for long-term electrical storage with improved reaction kinetics and reduced overpotentials. ${ }^{[5]}$ However, the charging of the photo-involved battery still requires external electricity power to a large extent, while the solar energy collection and electrical release are also two independent systems. The core of solar energy technology is to utilize solar light as an abundant energy source for continuous battery charging. Therefore, integrating these two promising energy systems into a single device as a monolithic battery for solar energy conversion and storage would be of great value.

Semiconductor catalysts with appropriate energy band positions are required to supply proper oxidation-reduction potential during the photocatalytic process. ${ }^{[6,7]}$ The majority of narrow-bandgap photocatalysts with suitable band positions are unstable under illumination, such as $\mathrm{CdS}, \mathrm{CdSe}$ and $\mathrm{Cu}_{2} \mathrm{O},{ }^{[8 \mathrm{a}-\mathrm{c}]}$ due to their easy self-redox process, which is known as a photocorrosion, while photocatalysts are typically reduced using the light and cannot selfoxidize. Rarely, the photo-generated holes of photocorrosive materials such as cuprous oxide and bismuth oxide oxidize or reduce themselves under illumination. ${ }^{[9,10]}$ These processes involve multiple steps of important electron transfer for energy conversion and storage using solar energy coupled with a proper fixation method, ${ }^{[11]}$ although these have yet to be realized. 
To this end, for the first time, we propose a new-concept of Solar-Metal-Air Batteries (SMABs), integrating the properties of solar cell and rechargeable battery. By rational electrode material design, the SMABs are expected to achieve solar energy storage and conversion through self-redox reactions. The key problem is the exploration of a recyclable valence-changed (self-corrosion) photoelectric-catalyst. The valence changes caused by the photocorrosion process can convert solar energy into chemical energy, which is then converted to electric energy by the charging process. Recently, introducing photo-assisted electrodes to restrain high charge overpotential in metal-air batteries has occasionally been reported ${ }^{[12]}$ the battery operation mechanism, however, remains to be a great challenge due to the additional charging process. In this regard, it should be significant to design a nextgeneration hybrid device based on self-corrosion electrode materials, which is meaningful for directly harvesting solar energy and achieving cyclic charging and discharging without an external power supply.

Herein, we discover that $\mathrm{BiOCl}$ exhibits the photosensitive, self-photocorrosion and regeneration properties for the novel type of SMABs. The cyclic photocorrosion processes between $\mathrm{BiOCl}\left(\mathrm{Bi}^{3+}\right)$ and $\mathrm{Bi}$ are achieved by alternating illumination and dark standing. In order to find an efficient and scalable immobilization method of the electrode materials, calcium alginate hydrogel is adopted as an anode to construct $\mathrm{BiOCl}$ photocorrosion hydrogel film electrode. Such an electrode is employed for the fabrication of SMABs owing to its excellent stability and safety as well as its favorable redox potentials with $\mathrm{Pt} / \mathrm{O}_{2}$ as counter electrode and $0.5 \mathrm{M} \mathrm{KOH}$ as the electrolyte. Two main modes are proposed in this work, (i) 'energy storage' mode with charging and discharging separated; and (ii) 'instant energy conversion' mode. Repeated self-photocorrosion and recovery processes of $\mathrm{BiOCl}$ (conversion between $\mathrm{Bi}^{3+}$ and $\mathrm{Bi}^{0}$ ) are the key to this class of SMABs developed in this work as they offer a convenient strategy to achieve charging and discharging processes driven entirely by solar energy coupled with oxygen evolution reaction (OER)/oxygen reduction 
reaction $(\mathrm{ORR})$ processes. We further demonstrated that the battery performance parameters, such as discharge time, can be further extended by increasing the illumination time (simulated AM 1.5 illumination), reactant content or electrode area, etc.

\section{Results and Discussion}

\subsection{Charging and discharging mechanism in SMABs}

Figure 1 schematically illustrates the basic structure and charge/discharge mechanism of the SMABs. A sandwich-like battery architecture with a BiOCl-based hydrogel film as anode, a Pt layer as cathode, and $\mathrm{KOH}$ solution $(0.5 \mathrm{M})$ as electrolyte is presented. Specifically, in Figure 1a, the photoelectrons arising from the conduction band of $\mathrm{BiOCl}$ during illumination drive the reduction process from $\mathrm{Bi}^{3+}$ to $\mathrm{Bi}$. Meanwhile, $\mathrm{O}_{2}$ is released via water oxidation reaction with the assistance of photo-generated holes. In the absence of light illumination, through the discharge process, electrochemical oxidation from $\mathrm{Bi}$ to $\mathrm{Bi}^{3+}$ on the $\mathrm{BiOCl} / \mathrm{Bi}$ hydrogel film occurs owing to the rather negative electrochemical potential of $\mathrm{Bi} / \mathrm{Bi}^{3+}$ than $\mathrm{O}_{2} / \mathrm{H}_{2} \mathrm{O}$. Consequently, the chemical energy is converted into electricity and the SMABs can be used to power electrical devices, as depicted in Figure 1b. Overall, solar energy can be stored and converted into electricity via such deliberately designed SMABs, which is achieved by light-responsive materials under illumination (charge) or non-illumination (discharge). 


\section{a Charging process}

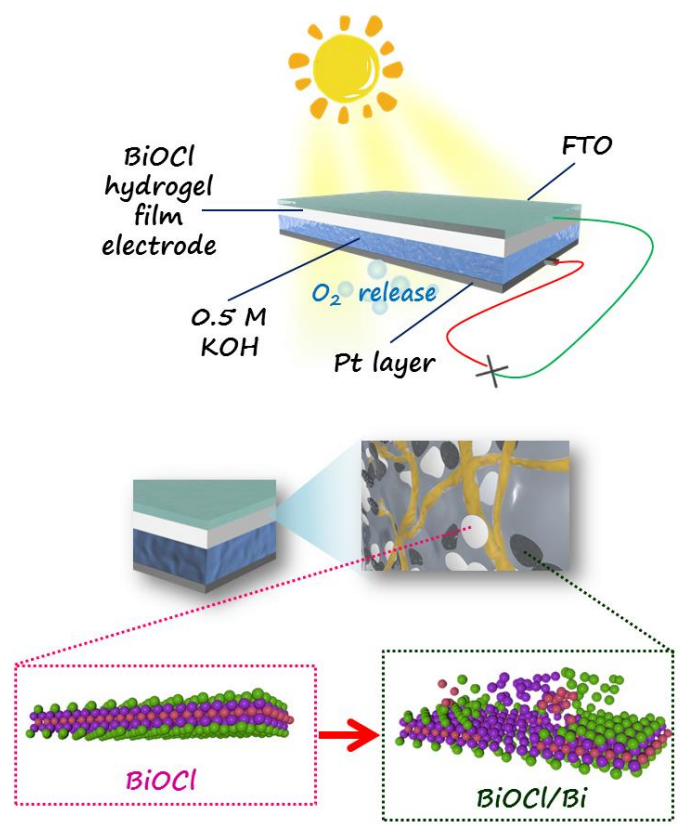

\section{b Discharging process}
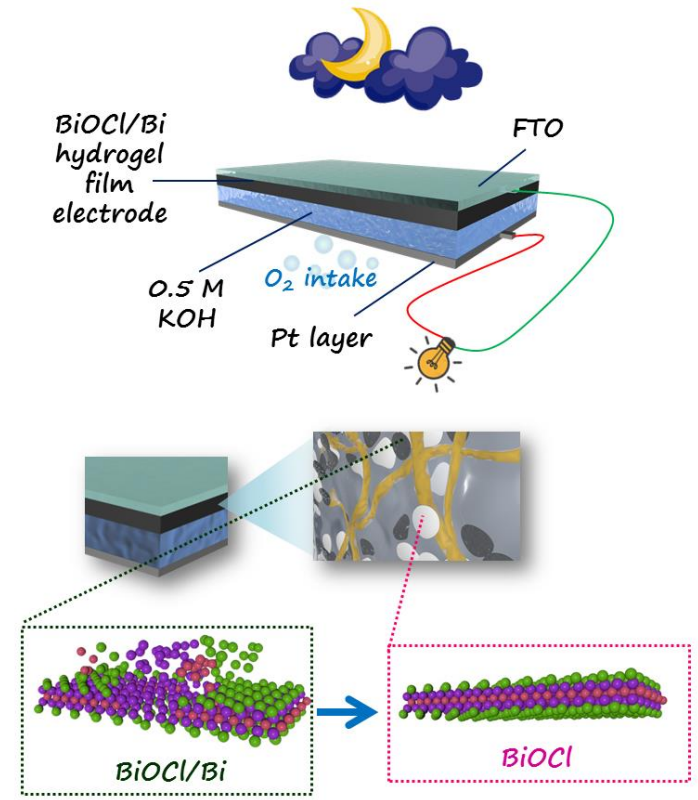

Figure 1. Schematic illustration of the (a) charge and (b) discharge mechanisms of the SMABs.

\subsection{Photocorrosion gel film electrode design}

The optical images of the as-prepared BiOCl hydrogel film electrode are shown in Figure S1. The BiOCl hydrogel film electrode is originally white, and it darkens upon illumination. The preparation process of the $\mathrm{BiOCl}$ hydrogel film electrode is depicted in Figure $\mathbf{S 2}$. Specifically, the hydrophilic $\mathrm{BiOCl}$ and sodium alginate were dispersed in water homogeneously, which was then injected into a conductive fluorine-doped tin oxide (FTO) substrate. Then the BiOCl coated FTO substrate was immersed in an aqueous solution of calcium chloride, and the gelation process was carried out for $30 \mathrm{~min}$ to form the calcium alginate@BiOCl hydrogel film electrode (i.e. BiOCl hydrogel film electrode), ${ }^{[13]}$ in which the $\mathrm{BiOCl}$ are wrapped by calcium alginate hydrogel network. The hydrophilicity of $\mathrm{BiOCl}$ was verified by the contact angle measurement shown in Figure S3; and the contact angle of the $\mathrm{BiOCl}$ powder was $34.2 \sim 36.6^{\circ}$, indicating that the $\mathrm{BiOCl}$ is hydrophilic. 
The self-photocorrosion and regeneration properties of the $\mathrm{BiOCl}$ were investigated using the as-prepared $\mathrm{BiOCl}$ hydrogel film electrode as the photo-responsive material (Figure 2a and Figure S4). The as-prepared white $\mathrm{BiOCl}$ hydrogel film on FTO substrate darkened upon illumination. The photographs of the film electrode of SMABs during discharging/charging processes are shown in Figure S5, demonstrating that the film darkens more with longer illumination times. Thus, we consider that the changes in the valence state of bismuth cause the color change of the film electrode. ${ }^{[14]}$ It is reported that $\mathrm{BiOCl}\left(\mathrm{Bi}^{3+}\right)$ and its other chemical valences $\left(\mathrm{Bi}^{2+}, \mathrm{Bi}^{+}, \mathrm{Bi}^{0}\right)$ involved compounds coexist or exist alone in the film due to the BiOCl self-photo-reduction properties. ${ }^{[14]}$ It is worth mentioning that the darkened $\mathrm{BiOCl}$ hydrogel film electrode (after illumination for $15 \mathrm{~min}$ ) recovers and returns to white film after standing for $12 \mathrm{~h}$ in the dark at room temperature (RT) (Figure 2a). As the pictures of the BiOCl hydrogel film electrode during the process shown in Figure S5, the illuminated (15 min) $\mathrm{BiOCl}$ (termed "BiOCl-15 min") hydrogel film electrode becomes light in color after standing for $4 \mathrm{~h}$, and it turns white again after standing for $12 \mathrm{~h}$, which indicates that the $\mathrm{BiOCl}$ exhibits the self-redox properties. Upon alternating the exposure to illumination and dark standing, the film electrode turns from black to white reversibly, suggesting a recyclable photo-responsive property of the electrode material.

The surface morphology and microscopic structure of the as-synthesized $\mathrm{BiOCl}$ and $\mathrm{BiOCl}$ hydrogel film electrode were analyzed using scanning electron microscopy (SEM) and transmission electron microscopy (TEM), as displayed in Figure 2b-g. The average diameter of pristine $\mathrm{BiOCl}$ nanosheets ranges from 200 to $500 \mathrm{~nm} .^{[15]}$ More importantly, for illuminated $\mathrm{BiOCl}$ nanosheets, their average size is decreased to $\sim 100-300 \mathrm{~nm}$ and a certain amount of $\mathrm{BiOCl}$ forms subsphaeroidal nanospheres, as shown in Figure $\mathbf{2 b}$. This morphological evolution implies the photocorrosion reaction of $\mathrm{BiOCl}$ causing the changes in the surface chemistry. Therefore, it is also meaningful to investigate the morphology and the thickness of the BiOCl hydrogel electrode film. In Figure 2c-d, the BiOCl hydrogel film 
electrode, featuring an average thickness of $78 \mu \mathrm{m}$, is composed of irregular calcium alginate gel network. The BiOCl nanosheets (highlighted by blue) sandwiched by the layers of calcium alginate hydrogel (highlighted in pink) forms a layered microstructure. After wrapping in gel network, the morphology of $\mathrm{BiOCl}$ nanosheets remains to be the same as before. In Figure S6, it can be seen that the thickness of the prepared electrode is about $1 \mathrm{~mm}$ before drying. The SEM image also shows that the surface of the BiOCl hydrogel film electrode is in an irregular shape, as shown in Figure S7. Moreover, the BiOCl particles on the surface are covered by the calcium alginate hydrogel. It was observed that $\mathrm{Bi}, \mathrm{O}, \mathrm{Cl}$, and Ca elements are distributed evenly in the cross section of the $\mathrm{BiOCl}$ hydrogel film electrode by SEM elemental mapping (Figure 2e), which indicates the homogenous incorporation of $\mathrm{BiOCl}$ within the calcium alginate hydrogel. As illustrated in the TEM images of BiOCl with different magnifications (Figure S8a), BiOCl features disc-shape structures with a diameter of 100-200 nm. Figure S8b shows the high-resolution TEM (HR-TEM) image of the BiOCl, in which a lattice spacing of $0.736 \mathrm{~nm}$ can be observed, corresponding to the (001) crystal plane of BiOCl. According to the TEM images in Figure 2f, the disc-shape BiOCl (diameter $\sim 100-200 \mathrm{~nm}$ ) is changed under illumination; some small particles with diameters of $\sim 5 \mathrm{~nm}$ are generated on the $\mathrm{BiOCl}$ nanosheets. These small particles are typically observed as $\mathrm{Bi}$ nanoparticles, ${ }^{[16,17]}$ which explains the morphology changes of the $\mathrm{BiOCl}$ after illumination, as observed in Figure 2b. The $\mathrm{BiOCl}$ after illumination (i.e. $\mathrm{Bi} / \mathrm{BiOCl}$ heterostructure) displays two different lattice fringes with the lattice spacing of 0.736 and $0.393 \mathrm{~nm}$, which can be assigned to the (001) crystal plane of $\mathrm{BiOCl}$ nanosheets and (003) crystal plane of the Bi nanoparticles (Figure 2g), ${ }^{[18]}$ further confirming the existence of elemental Bi. 


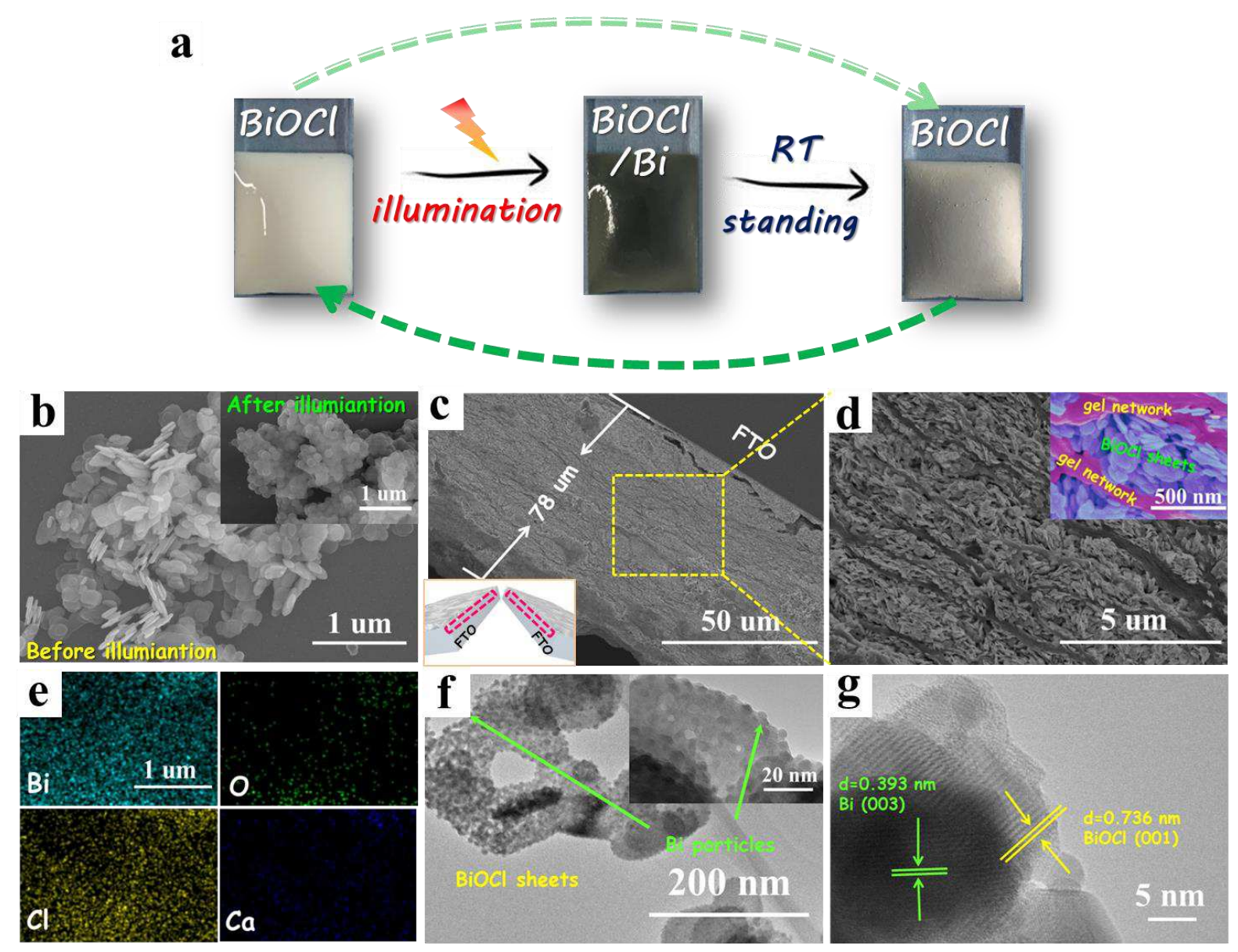

Figure 2. (a) Schematic illustration for the self-photocorrosion and recovery processes of $\mathrm{BiOCl}$ hydrogel film electrode; (b) SEM images of $\mathrm{BiOCl}$ powder. The inset image is the $\mathrm{BiOCl}$ after 30 min illumination; (c, d) Cross sectional SEM images of $\mathrm{BiOCl}$ hydrogel film electrode with different magnifications; (e) SEM elemental mapping images of $\mathrm{BiOCl}$ hydrogel film electrode; (f, g) TEM images of BiOCl after 30 min illumination with different magnifications.

X-ray diffraction (XRD) patterns of $\mathrm{BiOCl}$ and the corresponding illuminated samples are presented in Figure 3a, where the diffraction peaks of the as-prepared $\mathrm{BiOCl}$ can be well indexed to a tetragonal phase of BiOCl (JCPDS No. 73-2060). ${ }^{[19]}$ After 30 min illumination, a broad peak appeared at around $22.5^{\circ}$ (Figure $\mathbf{3 b}$ corresponds to the (003) lattice plane of a trigonal Bi (JCPDS Card No. 85-1330). ${ }^{[20]}$ This result suggests that a certain amount of BiOCl is reduced and metallic $\mathrm{Bi}$ is formed, which is in agreement with the observed Bi NPs via TEM. The reappearance of the strong (001) diffraction peak, after standing in dark $(12 \mathrm{~h})$, 
implies the formation of $\mathrm{BiOCl}$ phase as well as the reversible conversion between $\mathrm{BiOCl} / \mathrm{Bi}$ and $\mathrm{BiOCl}$. In order to further determine the presence of elemental $\mathrm{Bi}$ in the $\mathrm{BiOCl}$ after illumination, X-ray photoelectron spectroscopy (XPS) was conducted to characterize bonding states of the elements in the sample. The chemical compositions and elemental valence status of $\mathrm{BiOCl}$ were analyzed via XPS, as shown in Figure 3c and Figure S9. The binding energy (BE) and intensity of $\mathrm{Bi} 4 \mathrm{f}$ doublets for $\mathrm{BiOCl}$ (red line) and $\mathrm{BiOCl}$ (standing after illumination) maintain almost identical, indicating the chemical composition of $\mathrm{BiOCl}$ electrode can be recovered by standing $12 \mathrm{~h}$ after illumination. For the case of illuminated BiOCl electrode (illumination $30 \mathrm{~min}$ ), two new shoulder peaks appeared at $\sim 158$ and $\sim 163.8$ $\mathrm{eV}$ can be ascribed to the metallic Bi 4f doublets (Figure 3d), certifying that part of metallic $\mathrm{Bi}$ is generated after illumination. ${ }^{[23]}$ These results are consistent with the XRD results, further confirming that elemental $\mathrm{Bi}$ is generated in $\mathrm{BiOCl}$ under illumination. The $\mathrm{O} 1 \mathrm{~s}$ spectrum of the $\mathrm{BiOCl}$ illuminated for $30 \mathrm{~min}$ is shown in Figure S10, which can be fitted into two peaks at binding energies of $\sim 528.2 \mathrm{eV}$ and $\sim 530.4$ for the $\mathrm{O}^{2-}$ and $\mathrm{O}_{2}{ }^{2-}$ ions, respectively. ${ }^{[24]} \mathrm{In}$ Figure S11, two dominant peaks located at 198.2 and $200 \mathrm{eV}$ can be assigned to $\mathrm{Cl} 2 \mathrm{p}_{3 / 2}$ and $\mathrm{Cl} 2 \mathrm{p}_{1 / 2}$, respectively, both of which correspond to the $\mathrm{Cl}^{-[}{ }^{[25]} \mathrm{XPS}$ results of elemental $\mathrm{Bi}$ and $\mathrm{O}_{2}{ }^{2-}$ ions prove that the existence of redox products caused by an illumination. The possible mechanism can be described as follows: Under illumination, the photo-generated electrons in the conduction band $(\mathrm{CB})$ of the $\mathrm{BiOCl}\left(\mathrm{Bi}^{3+}\right)$ reduced to $\mathrm{Bi}\left(\mathrm{Bi}^{0}\right)$ owing to its self-reduction; and the photo-generated holes left in the valence bands (VB) oxidize $\mathrm{O}^{2-}$ to $\mathrm{O}_{2}$, with possible $\mathrm{O}_{2}{ }^{2-}$ as the intermediate during the recovery process ( $12 \mathrm{~h}$ or more standing in the dark). Due to the confinement effect of the gel film, $\mathrm{O}_{2}$ will drive the conversion of $\mathrm{Bi}^{0}$ to $\mathrm{Bi}^{3+}$ to form BiOCl.

The band structure of $\mathrm{BiOCl}$ was analyzed by using a ultraviolet-visible spectrophotometry (UV-vis), as shown in Figure 3e. The absorption edge appears at $\sim 383 \mathrm{~nm}$, and the bandgap of the $\mathrm{BiOCl}$ is estimated to be $3.4 \mathrm{eV}$ according to the intercept of the inset plot $\left((\alpha \mathrm{h} v)^{1 / 2} v s\right.$. 
photoenergy) in Figure 3e. ${ }^{[16,25]}$ The UV-vis absorption spectroscopy of $\mathrm{BiOCl}$ after illumination is shown in Figure S12, where the presence of elemental Bi leads to a continuous absorption band in the range of 400 to $600 \mathrm{~nm}$, which is in accordance with the darkened color. ${ }^{[26]}$
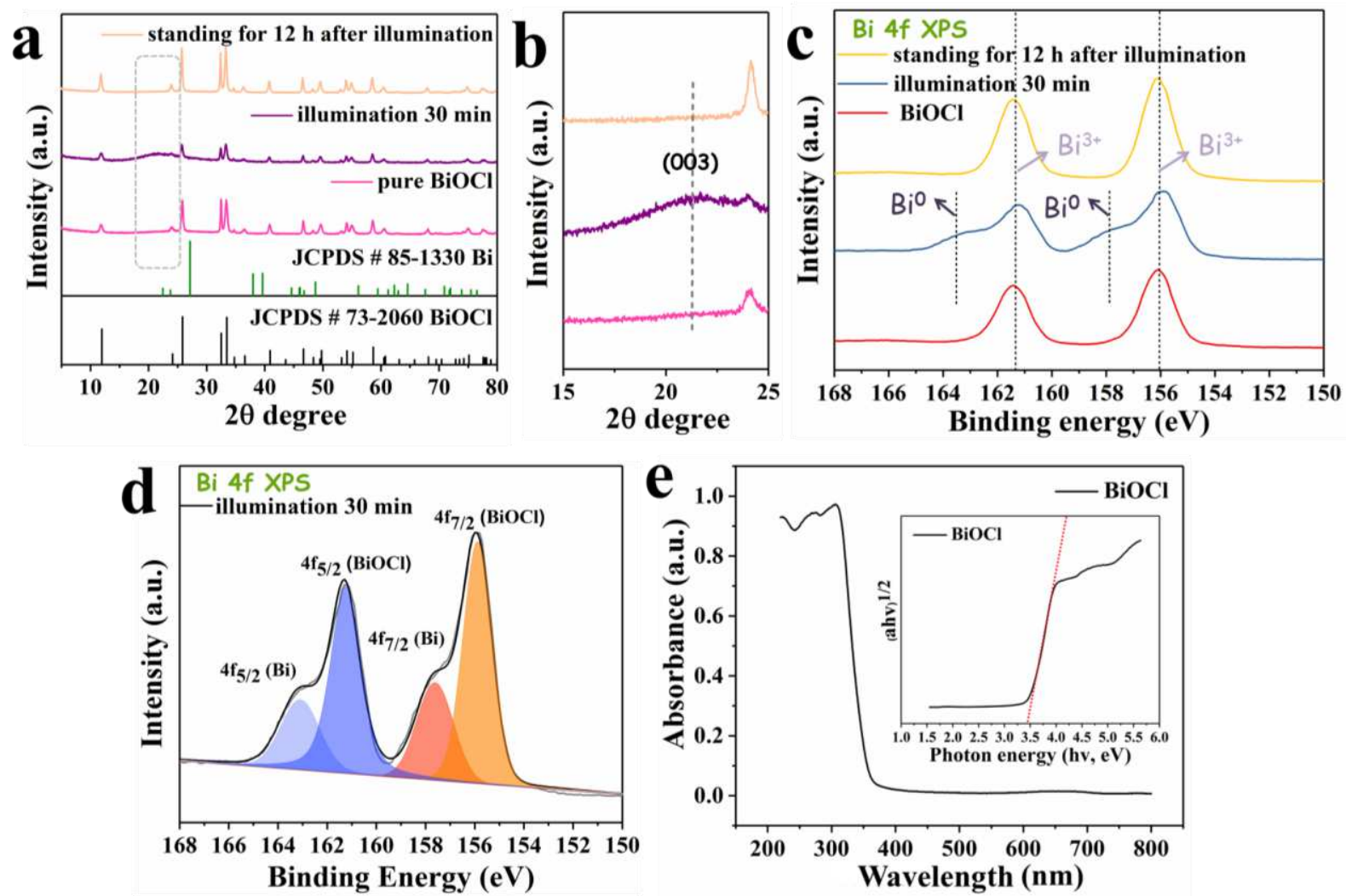

Figure 3. XRD patterns of (a) BiOCl powder, illumination for 30 min powder (BiOCl-30 min) and $\mathrm{BiOCl}-30$ min standing for $12 \mathrm{~h}$ and (b) partial magnified details; High resolution XPS spectra of (c) Bi $4 \mathrm{f}$ of $\mathrm{BiOCl}$ powder, BiOCl-30 min and BiOCl-30 min standing for $12 \mathrm{~h}$ and (d) $\mathrm{Bi} 4 \mathrm{f}$ of $\mathrm{BiOCl}-30 \mathrm{~min}$; (e) UV-vis absorption spectra of $\mathrm{BiOCl}$ powder (the inset is the lots of $(\alpha E)^{1 / 2}$ against photon energy $(E)$ for the $\mathrm{BiOCl}$, where $\alpha$ is the absorbance).

Metal-air batteries (MABs) generate electricity through a redox reaction between metal and oxygen. ${ }^{[27]}$ In a typical discharging process, the metal anode is oxidized and releases electrons to the external circuit; oxygen accepts electrons at cathode (ORR). When the cell is charged, the process is reversed, with metal generation and oxygen evolving (OER). ${ }^{[28]}$ However, some insoluble solid metal oxides or metal peroxides are generated at metal electrode during 
discharging process, which reduces the rechargeability performance of the MABs. ${ }^{[29]}$ Meanwhile, the air-involved electrode is also important for constructing the SMABs.

In order to establish energy band structure of the SMABs, a series of photoelectrochemical experiments were conducted. Figure 4a displays the Mott-Schottky plot for the BiOCl, and the positive slope of $\mathrm{BiOCl}$ corresponds to a n-type semiconductor in the hydrogel film electrode. ${ }^{[30,31]}$ The flat band potential of $\mathrm{BiOCl}$ can be approximately equal to the $\mathrm{CB} \cdot{ }^{[32,33]}$ The $\mathrm{CB}$ position of $\mathrm{BiOCl}$ was estimated at $-1.12 \mathrm{eV}$ versus $\mathrm{Ag} / \mathrm{AgCl}$ electrode based on the Mott-Schottky plot. The VB level can be deduced by reducing the bandgap, and thus, the VB of $\mathrm{BiOCl}$ was calculated to be $2.28 \mathrm{eV}$ ( $v s . \mathrm{Ag} / \mathrm{AgCl}$ ) considering the band-bap of $3.4 \mathrm{eV}$. It implies that with a proper reduction potential of $\mathrm{Bi}$, the photo-generated electrons in the $\mathrm{CB}$ can induce its self-reduction, and OER would take place, if the VB is lower than the oxidation potential of $\mathrm{H}_{2} \mathrm{O} / \mathrm{O}_{2}$.

The ORR, OER and electrochemical properties of the $\mathrm{BiOCl}$ hydrogel electrode in the SMABs were evaluated in a three-electrode system with $\mathrm{O}_{2}$-saturated $0.5 \mathrm{M} \mathrm{KOH}$ as an electrolyte, benchmark ORR catalyst $\mathrm{Pt}$ as a cathode, and $\mathrm{Ag} / \mathrm{AgCl}$ as a reference electrode. ${ }^{[34]}$ The linear sweep voltammetry (LSV) curves of the BiOCl hydrogel film electrode for OER in Figure 4b shows that its onset potential of OER without illumination was $0.81 \mathrm{~V}$ (vs. $\mathrm{Ag} / \mathrm{AgCl}$ ), and the onset potential of OER upon illumination was $0.32 \mathrm{~V}$ (vs. $\mathrm{Ag} / \mathrm{AgCl}$ ), indicating that the oxidation effect of the VB level of the semiconductor on $\mathrm{H}_{2} \mathrm{O}$ was significantly enhanced by illumination due to the photo-generated holes being involved in the OER process. For the ORR with Pt electrode, the onset potential was around $-0.03 \mathrm{~V}$ (vs. $\mathrm{Ag} / \mathrm{AgCl}$ ) as shown in Figure $\mathbf{4 c}$, which is a typical value of conventional Pt electrode for the ORR. ${ }^{[35]}$ The redox potentials of elemental $\mathrm{Bi}$ were identified using the cyclic voltammetry (CV) (Figure 4d), in which the BiOCl-30 min hydrogel film electrode was used as a positive electrode. The oxidation potential of elemental $\mathrm{Bi}$ was measured to be $-0.45 \mathrm{~V}(v s . \mathrm{Ag} / \mathrm{AgCl})$, which is more negative than the ORR potential $(-0.03 \mathrm{~V})$ (vs. $\mathrm{Ag} / \mathrm{AgCl})$. Therefore, according 
to electrochemistry theory, the potential difference between $\mathrm{Bi} / \mathrm{BiOCl}$ electrode and air electrode can induce the self-oxidation of $\mathrm{Bi}^{0}$ to $\mathrm{Bi}^{3+}$ and $\mathrm{ORR}$ reaction to provide an electricity output. ${ }^{[36]}$ It implies that $\mathrm{Pt} / \mathrm{O}_{2}$ cathode works efficiently for ORR, which is effective in constructing SMABs. Transient photovoltage (TPV) was further used to determine charge carrier diffusion properties, which performed in a self-assembling parallelplate capacitor (details see Experimental section in SI). ${ }^{[37]}$ As shown in Figure 4e, the positive response of $\mathrm{BiOCl}$ hydrogel film electrode corresponds to an n-type semiconductor, which is consistent with the result of Mott-Schottky test (Figure 3e). As illustrated in Figure 4e, two response peaks were observed at $2 \times 10^{-7} \mathrm{~s}$ and $1 \times 10^{-4} \mathrm{~s}$. The peak located at $2 \times 10^{-7} \mathrm{~s}$ represents the charge drift process of built-in electric field along the surface, while the peak at $1 \times 10^{-4} \mathrm{~s}$ can be used to probe the process of charge diffusion between particles. By comparison, the process of charge diffusion of the $\mathrm{BiOCl}$ hydrogel film electrode lasts longer than other materials, such as $\mathrm{BiVO}_{4}, \mathrm{Fe}_{3} \mathrm{O}_{4}, \mathrm{TiO}_{2} \cdot{ }^{[38,39,40]}$ The $\mathrm{BiOCl}$ hydrogel film electrode obtains a significantly enhanced TPV response after illumination, indicating that the separation of photo-generated charges is promoted by the conductive elemental $\mathrm{Bi}$, which is beneficial to further discharge process. 

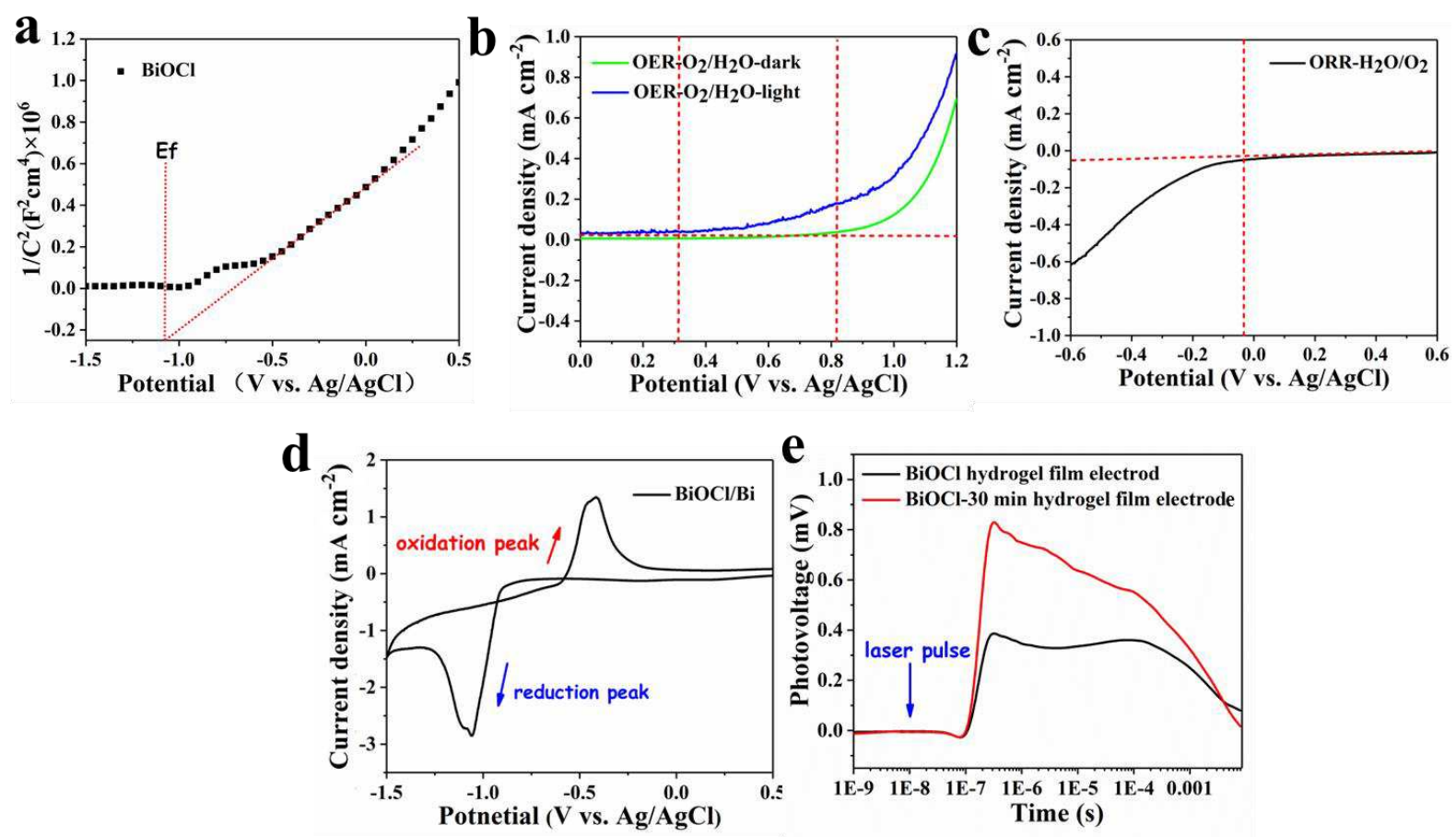

Figure 4. (a) Mott-Schottky plot for $\mathrm{BiOCl}$ in $0.5 \mathrm{M} \mathrm{Na}_{2} \mathrm{SO}_{4}$ aqueous solution $(\mathrm{pH}=6.8)$; (b) OER polarization curves of $\mathrm{BiOCl}$ hydrogel film electrode in dark (green curve) and under illumination (blue curve); (c) ORR polarization curve of reaction with double Pt electrode; (d) Cyclic voltammogram of $\mathrm{BiOCl}-30$ min hydrogel film electrode including $0.5 \mathrm{M} \mathrm{KOH}$ aqueous solution after illumination; (e) TPV of the BiOCl hydrogel film electrode before illumination (black curve) and after 30 min illumination (BiOCl-30 min, red curve) excited by $355 \mathrm{~nm}$ laser pulse.

\subsection{Battery performance}

Based on the aforementioned battery configuration, solar energy can be stored and/or converted into electricity via SMABs by using our well-designed BiOCl hydrogel film electrode. Specifically, in Figure 5, the working mode of the SMABs can be classified into "energy storage" and "instant energy conversion", where the discharge/charge process is separated and integrated, respectively. In terms of Mode one (Figure 5a (i)), the BiOCl hydrogel film electrode undergoes a photo-charging process when exposed to illumination for a period of time. The $\mathrm{BiOCl}$ is reduced by photo-generated electrons with the formation of metallic $\mathrm{Bi}$, while $\mathrm{O}_{2}$ gas is generated via water oxidation reaction induced by photogenerated holes. Upon discharge, as shown in Figure 5a (ii), the metallic Bi is self-oxidized 
at the anode and ORR occurs at cathode. Based on discharge/charge mode (Mode one), the proposed electrode reactions can be described as follows:

$$
\begin{aligned}
& \text { Anode: } \mathrm{Bi}-3 e^{-}+\mathrm{H}_{2} \mathrm{O}+\mathrm{Cl}^{-} \rightarrow \mathrm{BiOCl}+2 \mathrm{H}^{+} \\
& \text {Cathode: } \mathrm{O}_{2}+4 \mathrm{H}^{+}+4 e^{-} \rightarrow 2 \mathrm{H}_{2} \mathrm{O}
\end{aligned}
$$

In particular, the open circuit voltage of the BiOCl hydrogel film electrode (electrode area $~ 1$ $\mathrm{cm}^{2}$ ) increases and approaches $\sim 0.38 \mathrm{~V}$ after 15 min illumination, which is close to the gap between $\mathrm{Bi}$ oxidation potential (-0.45 V vs. $\mathrm{Ag} / \mathrm{AgCl})$ and $\mathrm{ORR}$ potential (-0.03 vs. $\mathrm{Ag} / \mathrm{AgCl})$, and then further dropped to $\sim 0.22 \mathrm{~V}$ (Figure 5b). After discharging reaction, the BiOCl hydrogel film turns white again (Figure S5). Upon light illumination, photo-darking immediately initiated. Our measurements examine the performance of $\mathrm{BiOCl}$ hydrogel film electrode at $15 \mathrm{~min}, 30 \mathrm{~min}$ and $60 \mathrm{~min}$ illuminations, and the discharge curves with different illumination times were measured (Figure 5c). The rechargeability performance of the SMABs is presented in Figure 5c. In the first cycle (red curve), after 15 min illumination (at AM 1.5), the discharge current density gradually decreased from 3.62 to $0.43 \mathrm{~mA} \cdot \mathrm{cm}^{-2}$, corresponding to the oxidation reaction of elemental $\mathrm{Bi}$ (the color of the $\mathrm{BiOCl}$ hydrogel film electrode changes from dark to white). In the second cycle (blue curve), the discharge current density with 30 min illumination decreased from 3.75 to $0.63 \mathrm{~mA} \cdot \mathrm{cm}^{-2}$, which shows a slight improvement in the initial discharging current. In the third cycle (green curve), illumination for 60 min shows significantly improved performance in comparison with illuminations for 15 or 30 min because of its enhanced discharging current at the beginning. The discharge current density with 60 min illumination decreases from 6.24 to $0.5 \mathrm{~mA} \cdot \mathrm{cm}^{-2}$. These imply that the illumination on $\mathrm{BiOCl}$ hydrogel electrode can promote its discharge performance and significantly enhance the initial discharging current. XRD and XPS tests (Figure $4 \mathbf{b}$, c) have already proved that the $\mathrm{BiOCl}$ active electrode material can be completely recovered after illumination, and these results demonstrate the good rechargeability of the SMABs. It is expected further optimization of the $\mathrm{BiOCl}$ hydrogel film electrode could yield better 
electrochemical properties, making SMABs promising for high performance energy conversion and storage applications. The electric charge (Coulomb) during the discharge process can be calculated according to the integral formula equation (1), as shown in the Supporting information. The Coulomb of the battery (illuminated-15 min) is $1.92 \mathrm{C}$, which confirms the substantial storage of solar energy.
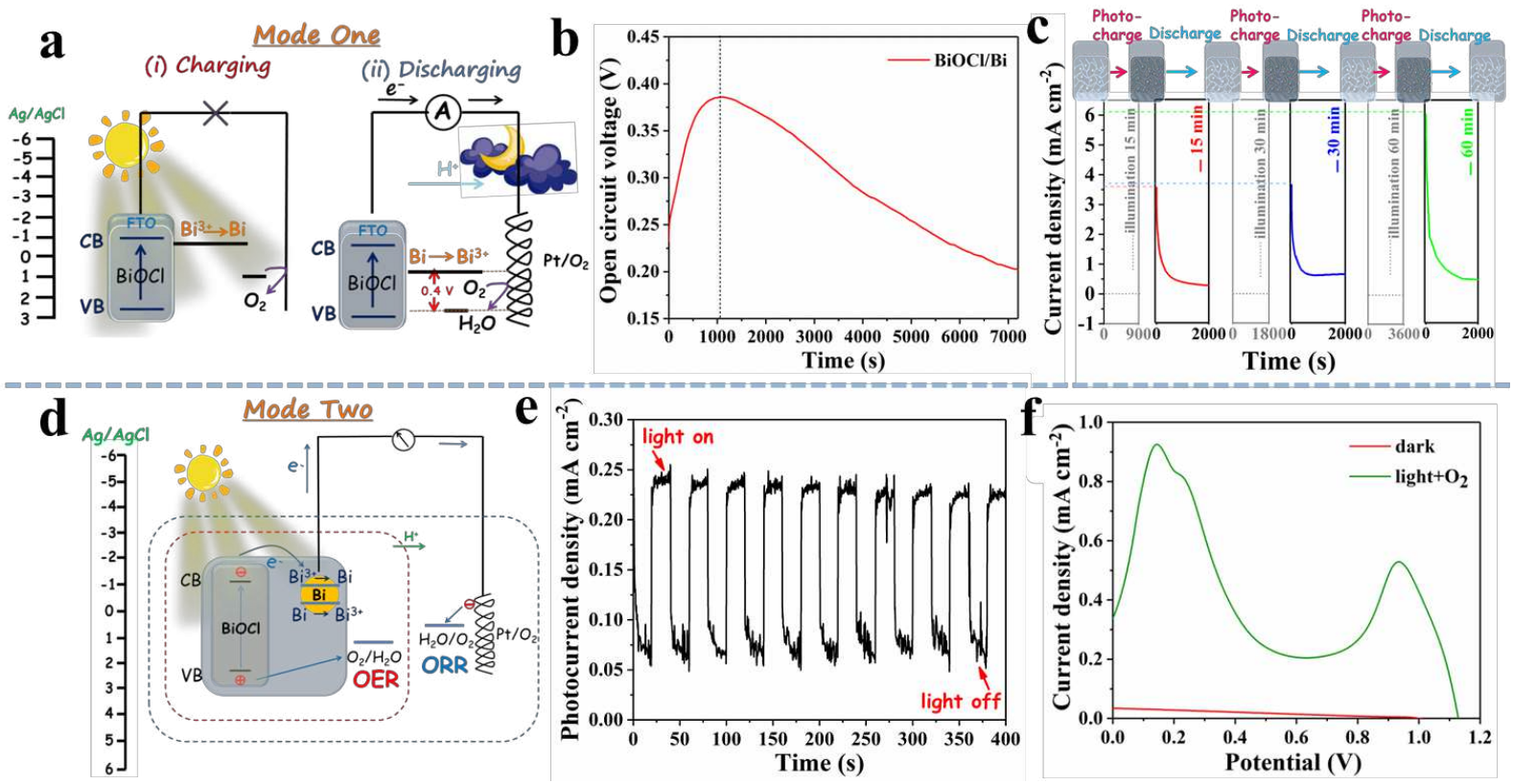

Figure 5. (a) Schematic energy level positions of Working Mode One ('energy storage') in SMABs; (b) Open circuit voltage curve of the SMABs with 15 minutes illumination in Mode One; (c) Rechargeability performance of the SMABs with different illumination times $(15,30$ and 60 minutes) in Mode One; (d) Schematic energy level positions of the Working Mode Two ('instant energy conversion') in SMABs; (e) l-t characteristic curves of the BiOCl hydrogel film electrode in $0.5 \mathrm{M} \mathrm{KOH}$ aqueous solution under light with on/off cycles in Mode Two; (f) I-V characteristic curves of the SMABs based on two electrode system of $\mathrm{BiOCl}$ hydrogel film photoanode and $\mathrm{Pt}$ cathode with the electrolyte of $\mathrm{O}_{2}$-saturated $0.5 \mathrm{M} \mathrm{KOH}$ under illumination (AM 1.5 sunlight illumination with a power density of $100 \mathrm{~mW} / \mathrm{cm}^{2}$ ) in Mode Two.

With regard to Mode Two, the "instant energy conversion" mechanism of the SMABs under real-time continuous illumination is depicted in Figure 5d. The position of the CB of $\mathrm{BiOCl}(-1.12$ vs. $\mathrm{Ag} / \mathrm{AgCl})$ is a bit higher than the reduction potential of metallic $\mathrm{Bi}(-1.0 \mathrm{~V} v s$. 
$\mathrm{Ag} / \mathrm{AgCl}$ ). Under illumination, the photoelectrons arising from the $\mathrm{CB}$ of $\mathrm{BiOCl}$ drive the self-reduction of $\mathrm{Bi}^{3+}$ to $\mathrm{Bi}^{0}$; and meanwhile, the formed metallic $\mathrm{Bi}$ is oxidized in air (Figure 5a(ii)) and generate electrons for the ORR. Furthermore, the position of the VB of BiOCl was $2.28 \mathrm{~V}$ vs. $\mathrm{Ag} / \mathrm{AgCl}$, which is more positive than the oxidation potential of $\mathrm{H}_{2} \mathrm{O}$ versus $\mathrm{Ag} / \mathrm{AgCl}$ electrode $\left(\varphi_{\mathrm{H}_{2} \mathrm{O} / \mathrm{O}_{2}}=0.22 \mathrm{~V}, 0.5 \mathrm{M} \mathrm{KOH}\right)$; so the photo-generated holes with strong oxidation capability can enable the conversion of $\mathrm{H}_{2} \mathrm{O}$ to $\mathrm{O}_{2}$. Consequently, $\mathrm{O}_{2}$ is produced at the anode and consumed at the cathode, forming a complete energy cycle within the SMABs. Figure 5e shows the I-t characteristic curve of the BiOCl hydrogel film photoelectrode. It can be seen that the SMABs show a real-time light-response, which indicates that the illuminated- $\mathrm{BiOCl}$ (i.e. $\mathrm{BiOCl} / \mathrm{Bi}$ ) hydrogel film electrode can generate and separate photo-induced charges. The photoelectric properties of the SMABs under dark and under AM 1.5 sunlight illumination (with $\mathrm{O}_{2}$-bubbled) were also studied. Figure $\mathbf{5 f}$ shows the I-V characteristic curve of the battery by using traditional solar cell testing method. A twoelectrode system including the $\mathrm{BiOCl}$ hydrogel film electrode as the working electrode and $\mathrm{Pt}$ electrode as the counter electrode was adopted, while a Xenon lamp (AM 1.5) was used as the light source to irradiate the $\mathrm{BiOCl}$ hydrogel film electrode. It is observed that when the $\mathrm{BiOCl}$ hydrogel film electrode is used as a photoanode and $\mathrm{Pt} / \mathrm{O}_{2}$ as a cathode under illumination, the short-circuit current density of the cell was $0.3 \mathrm{~mA} \cdot \mathrm{cm}^{-2}$ (the maximum output current density of the $\mathrm{BiOCl}$ hydrogel film electrode is $0.9 \mathrm{~mA} \cdot \mathrm{cm}^{-2}$ ). Unlike the typical $\mathrm{I}-\mathrm{V}$ curves of traditional solar cell, two response peaks were detected for our SMABs (green line), indicating that the generated elemental $\mathrm{Bi}$ is involved in the charging and discharging processes. Specifically, the charging and discharging characteristics of the SMABs can be confirmed by the galvanostatic charge-discharge test as a metal-air battery, as shown in Figure S13. The charge-discharge curves further demonstrate that the SMABs have the charge-discharge characteristics like battery. The photovoltage of the SMABs under illumination was lower than that in the dark, which further confirms that the photo-charging 
reduces the charging voltage. During the discharge process, $\mathrm{Bi}$ is oxidized to $\mathrm{Bi}^{3+}$ and gradually resumed, and the battery recyclable charging is due to the reduction process of $\mathrm{Bi}^{3+}$ to $\mathrm{Bi}$. The $\mathrm{BiOCl}$ hydrogel film electrode-based SMABs were studied according to the principle of Bi-air battery, the upper theoretical limit capacity of the SMAB can reach up to $384.75 \mathrm{mAh} \cdot \mathrm{g}^{-1}$ (Eq. S2), which was higher than that of the lithium ion battery $\left(\mathrm{LiCoO}_{2}\right.$, $\left.274 \mathrm{mAh} \cdot \mathrm{g}^{-1}\right) \cdot{ }^{[41]}$ However, it should be noted that our SMABs are powered entirely by renewable solar energy without additional electric drive to meet sustainable energy needs. ${ }^{[42]}$ The efficient photoelectric conversion and discharge ability of the SMABs are driven by the renewable photo-response $\mathrm{BiOCl}$ hydrogel electrode material. Photo-rechargeable $\mathrm{BiOCl}$ hydrogel film electrode can convert the chemical energy of photocorrsion products to electric energy, making it possible to construct a next generation solar energy device.

This work is dedicated to propose, for the first time, the new working principle of SMABs. Future research directions to improve the device performance would include: (1) exploiting the factors of electrode material affecting electrochemical performance (e.g. content, morphology, size, valence state, structure, surface area, etc.); (2) searching for suitable anode/cathode electrode materials, which are reasonable substitutes for conventional semiconductor and expensive platinum to accelerate corresponding electrochemical reaction rates, and help the electrochemical transfer of solar energy; (3) optimizing the gelation fixing strategies of photo-responsive electrode materials by building strong gel-electrode films that can adopt to extreme conditions (e.g. adding thermal conductive adhesion layer or creating covalent polymerization between the hydrogel and the semiconductor surfaces) $;^{[43]}$ and (4) developing multifunctional architectures of SMABs. Air, as a general component of the battery, is involved in electrochemical reactions, which could make the battery akin to a fuel cell, with the 'fuel' being the air. It may induce the integration of the advance energy devices, and bring a positive impact on new energy policies. 


\section{Conclusions}

In summary, a monolithic solar battery, integrating solar energy harvesting and electrical energy storage, is developed based on the unique combination of the photocorrosive and oxidation process of $\mathrm{BiOCl}$ semiconductors. The $\mathrm{BiOCl}$ hydrogel film electrode is sensitive to light illumination to allow self-oxidation and self-reduction, while its lifetimes are compatible with ORR and OER processes for the charging and discharging processes. Upon illumination, the generated photoelectrons induced by photocorrosive reaction of the $\mathrm{BiOCl}$ thin film electrode dedicate to the self-reduction from $\mathrm{BiOCl}$ to $\mathrm{Bi}$ and the stored chemical energy. In the discharge process, the electrons associated with self-oxidation from $\mathrm{Bi}$ to $\mathrm{Bi}^{3+}$ flow into external circuit and generate electricity output. The conceptual combination of photocorrosion with self-oxidation of low-cost $\mathrm{BiOCl}$ allows the creation of a new monolithic solar battery architecture. The performance can be enhanced by increasing illumination time, material content, electrode construction and others. Overall, this work introduces a dual-functional SMABs, which are powered by solar energy and recyclable materials, opening up a new pathway for utilization of solar energy and promote the development of smart controllable clean energy technologies.

\section{Experimental Section/Methods}

Experimental details see Supporting Information.

\section{Acknowledgements}

This work was supported by the National Natural Science Foundation of China (No.51773085, 52071171), the Natural Science Fund of Liaoning University (LDGY2019016), Liaoning Revitalization Talents Program - Pan Deng Scholars (XLYC1802005), Liaoning BaiQianWan Talents Program (LNBQW2018B0048), Natural Science Fund of Liaoning Province for Excellent Young Scholars (2019-YQ-04), Key Project of Scientific Research of the Education Department of Liaoning Province (LZD201902), Australia Research Council through the 
Discovery Project scheme (DP190103186) and the Industrial Transformation Training Centres scheme (Grant No. IC180100005), and the Advanced Solar Facility at Swinburne University of Technology.

\section{References}

[1] M. I. Hoffert, K. Caldeira, A. K. Jain, E. F. Haites, L. D. D. Harvey, S. D. Potter, M. E. Schlesinger, S. H. Schneider, R. G. Watts, T. M. L. Wigley, D. J. Wuebbles, Nature 1998, $395,881$.

[2] D. Butler, Nature 2008, 454, 558.

[3] P. Chen, G. R. Li, T. T. Li, X. P. Gao, Adv. Sci. 2019, 6, 1900620.

[4] D. Linden, T. B. Reddy, Handbook of Batteries, McGraw-Hill, New York, 3rd edn, 2002.

[5] M. Yu, X. Ren, L. Ma, Y. Wu, Nat. Commun. 2014, 5, 5111;

[6] P. J. Yang, R. R. Wang, M. Zhou, X. C. Wang, Angew. Chem. Int. Edit. 2018, 130, 8810.

[7] F. F. Wang, Q. Li, D. S. Xu, Adv. Energy Mater. 2017, 7, 1700529.

[8] (a) L. Cheng, Q. J. Xiang, Y. L. Liao, H. W. Zhang, Energy Environ. Sci. 2018, 11, 1362; (b) D. Y. Li, S. Hussain, Y. J. Wang, C. Huang, P. Li, M. Y. Wang, T. He, Appl. Catal. B-Environ. 2021, 286, 119887; (c) J. L. Liu, M. Wen, H. X. Chen, J. Li, Q.-S. Wu, Chemplus Chem, 2014, 79, 298.

[9] Q. Cai,'W. T. Hong, C. Y. Jian, W. Liu, Nano Energy 2020, 70, 104485.

[10] C. Y. Toe, Z. K. Zheng, H. Wu, J. Scott, R. Amal, Y. Haung, Angew. Chem. Int. Edit. 2018, 57, 13613.

[11] S. Z. Wu, F.Zeng, H. P. Zhu, Z. Tong, J. Am. Chem. Soc. 2005, 127, 2048.

[12] D. D. Zhu, Q. C. Zhao, G. L. Fan, S. Zhao, L. B. Wang, F. J. Li, J. Chen, Angew. Chem. Int. Edit. 2019, 58, 36.

[13] X. W. Wang, H. G. Spencer, Polymer 1998, 39, 2759.

[14] S. X. Weng, B. B. Chen, L. Y. Xie, Z. Y. Zheng, P. Liu, J. Mater. Chem. A 2013, 1, 3068 . 
[15] Y. Ming, F. Wu, S. Banerjee, J. Park, P. Banerjee, Chem. Commun. 2015, 51, 2629.

[16] M. L. Sun, W. D. Zhang, Y. J. Sun, Y. X. Zhang, F. Dong, Chinese J. Catal. 2019, 40, 826.

[17] Y. Yu, C. Y.Cao, H. Liu, P. Li, F. F. Wei, Y. Jiang, W. G. Song, J. Mater. Chem. A, 2014, 2, 1677.

[18] W. Q. Fan, C. F. Li, H. Y. Bai, Y. Y. Zhao, B. F. Luo, Y. J. Li, Y. L. Ge, W. D. Shi, H. P. Li, J. Mater. Chem. A, 2017, 5, 4894.

[19] X. M. Mao, X. L. Li, Y. W. Wang, C. M. Fan, H. Zhang, Chem. Eng. J. 2014, 247, 241.

[20] V. L. Chandraboss, J. Kamalakkannan, S. Senthilvelan, Appl. Surf. Sci. 2016, 387, 944.

[21] X. W. Liu, H. Q. Cao, J. F. Yin, Nano Res. 2011, 45, 470.

[22] L. H. Yu, X. Y. Zhang, G. W. Li, Y. T. Cao, Y. Shao, D. Z. Li, Appl. Catal. B-Environ. 2016, 187, 301.

[23] G. Wittstoc, A. Strubing, R. Szargan, G. Werner, J. Electroanal. Chem. 1998, 444, 61.

[24] J. Hrbek, Y. W. Yang, J. A. Rodriguez, Surf. Sci. 1993, 296, 164.

[25] H. Wang, W. D. Zhang, X. W. Li, J. Y. Li, W. L. Cen, Q. Y. Li, F. Dong, Appl. Catal. B-Environ. 2018, 225, 218.

[26] L. Xu, P. C. Yan, H. N. Li, S. Y. Ling, J. X. Xia, J. X. Qiu, Q. Xu, H. M. Li, S. Q.Yuan, Mater. Lett. 2017, 196, 225.

[27] M. Zeng, Y. Liu, F. Zhao, K. Nie, N. Han, X. Wang, W. Huang, X. Song, J. Zhong and Y. Li, Adv. Funct. Mater. 2016, 26, 4397.

[28] F. Y. Cheng, J. Chen, Chem. Soc. Rev. 2012, 41, 2172.

[29] L. N. Han, L. B. Lv, Q. C. Zhu, X. Wei, X. H. Li, J. S. Chen, J. Mater. Chem. A, 2016, 4,7841 .

[30] D. S. Kong, Langmuir, 2008, 24, 5324.

[31] D. Chen and J. Li, J. Phys. Chem. C, 2010, 114, 10478.

[32] J. Premkumar, Chem. Mater 2004, 16,3980.

[33] S. Iimura, H. Tezuka, A. Nakagawa, S. Yoshihara, T. Shirakashi, Electrochemistry 2001, 69, 324. 
[34] B. Lim, M. Jiang, P. H. C. Camargo, E. C. Cho, J. Tao, X. Lu, Y. Zhu, Y. N. Xia, Science 2009, 324, 1302.

[35] V. A. Saveleva, V. Papaefthimiou, M. K. Daletou, W. H. Doh, C. U.-Bouillet, M. Diebold, S. Zafeiratos, E. R. Savinova, J. Phys. Chem. C 2016, 120, 15930.

[36] X. J. Li, Y. C. Tang, H. M. Lv, W. L. Wang, F. N. Mo, G. J. Liang, C. Y. Zhi, H. F. Li, Nanoscale 2019, 11, 17992.

[37] Y. Zhang, Y. Li, W. N. Sun, C. X. Yuan, B. X. Wang, W. Zhang, X.-M. Song, Langmuir 2017, 33, 12065.

[38] O. J. Sandberg, K. Tvingstedt, P. Meredith, A. Armin, J. Phys. Chem. C 2019, 123, 14261.

[39] D. Zhang, Y. M. Wang, Y. Wang, Y. Zhang, X.-M. Song, J. Alloy. Compd. 2020, 815 152377.

[40] (a) S. C. Wang, T. W. He, P. Chen, A. J. Du, K. Ostrikov, W. Huang, L. Z. Wang, Adv. Mater. 2020, 32, 2001385; (b) X. H. Peng, H. B. Yu, L. Ai, N. Li, X. Wang, Bioresource Technol. 2013, 144, 689; (c) S. Yang, Y. Hou, J. Xing, B. Zhang, F. Tian, X. H. Yang, H. G. Yang, Chem-Eur J. 2013, 19, 9366.

[41] J. Y. Li, C. Lin, M. Weng, Y. Qiu, P. H. Chen, K. Yang, W. Y. Huang, Y. X. Hong, J. Li, M. J. Zhang, C. Dong, W. G. Zhao, Z. Xu, X. Wang, K. Xu, J. L. Sun, Feng Pan, Nat. Nanotechnol. 2021, accepted.

[42] J. S. Lee, S. T. Kim, R. Cao, N. S. Choi, M. Liu, K. T. Lee, J. Cho, Adv. Energy Mater. 2011, 1,34 .

[43] S. R. Pu, J. Fu, Y. T. Liao, L. R. Ge, Y. H. Zhou, S. L. Zhang, S. L. Zhao, X. W. Liu, X. J. Hu, K. Liu, J. Chen, Adv. Mater. $2020,32,1907307$. 
The table of contents: The disc-shaped bismuth oxychloride, $\mathrm{BiOCl}$, is sensitive to illumination to drive self-redox (self-photocorrosion and recovery). Smart New Solar-MetalAir batteries (SMABs) based on BiOCl hydrogel film electrodes are assembled. The SMABs fully powered by solar energy can act as an energy storage device with the open circuit voltage of $0.38 \mathrm{~V}$.

Authors: Yalin Lan, ${ }^{\text {a, }}$ Munkhbayar Batmunkh, ${ }^{\text {b, }}$ Peng Li, ${ }^{\mathrm{c}}$ Bingzhi Qian, ${ }^{\mathrm{a}}$ Degang Bu, ${ }^{\mathrm{a}}$ Qin Zhao, ${ }^{\mathrm{a}}$ Hongwei Huang, ${ }^{\mathrm{d}}$ Wenping Sun, ${ }^{\mathrm{e}}$ Yu Zhang, ${ }^{\mathrm{a}} *$ Tianyi Ma, ${ }^{\mathrm{c}, *}$ Xi-Ming Song ${ }^{\mathrm{a}, *}$, Baohua $\mathrm{Jia}^{\mathrm{c}, *}$

Title:

Smart Solar-Metal-Air Batteries Based on BiOCl Photocorrosion for Monolithic Solar Energy Conversion and Storage

\section{ToC figure:}

\section{Charging process}

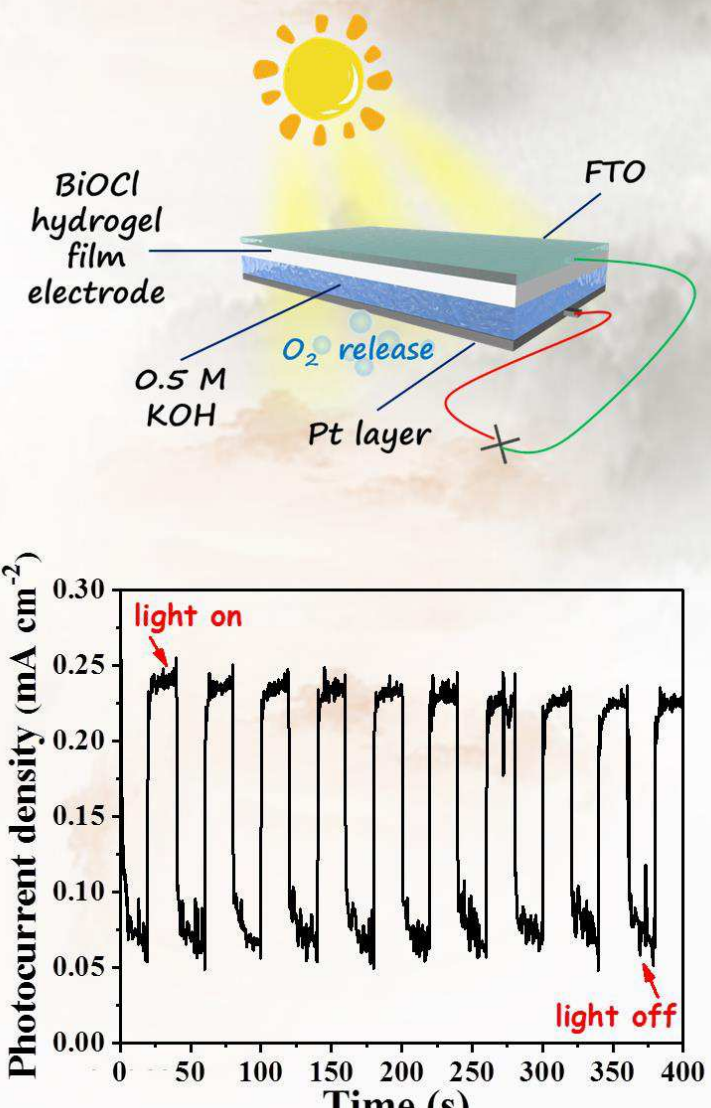

\section{Discharging process}

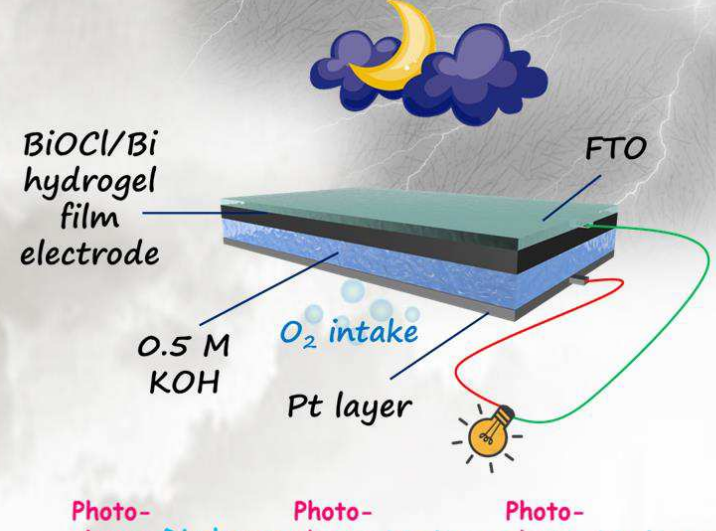

charge Discharge charge Discharge charge Discharge

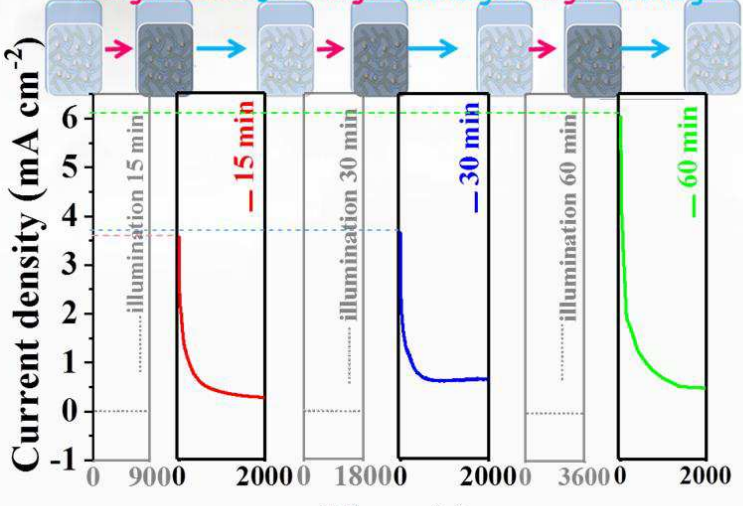

Time (s) 
Supporting Information

\section{Smart Solar-Metal-Air Batteries Based on BiOCl Photocorrosion for Monolithic Solar Energy Conversion and Storage}

Yalin Lan, ${ }^{\mathrm{a}, \uparrow}$ Munkhbayar Batmunkh, ${ }^{\mathrm{b}, \dagger}$ Peng Li, ${ }^{\mathrm{c}}$ Bingzhi Qian, ${ }^{\mathrm{a}}$ Degang Bu, ${ }^{\mathrm{a}}$ Qin Zhao, ${ }^{\mathrm{a}}$ Hongwei Huang, ${ }^{\mathrm{d}}$ Wenping Sun, ${ }^{\mathrm{e}}$ Yu Zhang, ${ }^{\mathrm{a}, *}$ Tianyi Ma, ${ }^{\mathrm{c}, *}$ Xi-Ming Song ${ }^{\mathrm{a}, *}$, Baohua Jia ${ }^{\mathrm{c}, *}$

${ }^{a}$ Liaoning Key Laboratory for Green Synthesis and Preparative Chemistry of Advanced Materials, College of Chemistry, Liaoning University, Shenyang 110036, China

${ }^{b}$ Centre for Catalysis and Clean Energy, School of Environment and Science, Griffith University, Gold Coast, QLD 4222, Australia

${ }^{c}$ School of Materials Science and Technology, China University of Geosciences, Beijing 100083, China

${ }^{d}$ Centre for Translational Atomaterials, Swinburne University of Technology, Hawthorn, VIC 3122, Australia

e School of Materials Science and Engineering, State Key Laboratory of Clean Energy Utilization, Zhejiang University, Hangzhou, 310027, P. R. China. 


\section{Summary}

S1. Supporting experimental section.

S2. Supporting Figure S1 S13. 


\section{Experimental section}

\section{Materials}

The chemicals (e.g., Bismuth nitrate pentahydrate, potassium chloride, ethylene glycol, ethyl alcohol, sodium alginate, calcium chloride, etc.) used in this study were purchased from Sinopharm Chemical Reagent Co., Ltd. (Shanghai, China) without further purification and fluorine-doped tin oxide (FTO) glasses were purchased from Degussa, OPV Tech New Energy Co, Ltd. The deionized water was used in all the experiments.

\section{Preparation of $\mathrm{BiOCl}$}

$\mathrm{BiOCl}$ was synthesized by a hydrolytic process according to the previous report. ${ }^{[1]}$ Briefly, $2 \mathrm{mmol}(0.9702 \mathrm{~g})$ bismuth nitrate pentahydrate $\left(\mathrm{Bi}\left(\mathrm{NO}_{3}\right)_{3} \cdot 5 \mathrm{H}_{2} \mathrm{O}\right)$ and $20 \mathrm{~mL}$ ethylene glycol (EG) were added into a glass beaker and sonicated for $30 \mathrm{~min}$. Then, $2 \mathrm{mmol}(0.1491 \mathrm{~g}) \mathrm{KCl}$ was added to the as-prepared solution, and further sonicated for $30 \mathrm{~min}$. The mixture was dropped into water, followed by stirring continuously for $12 \mathrm{~h}$ to get the completely precipitation. Finally, the precipitation was washed several times (water and ethanol) and dried at $55^{\circ} \mathrm{C}$ under oven before obtaining $\mathrm{BiOCl}$ powder.

\section{Preparation of $\mathrm{BiOCl}$ hydrogel film electrode}

The $\mathrm{BiOCl}$ hydrogel film electrode was synthesized by a simple gelation method. ${ }^{[2]}$ Sodium alginate $(2 \mathrm{~g})$ and $\mathrm{H}_{2} \mathrm{O}(98 \mathrm{~mL})$ were added in a glass beaker and stirred continuously for $12 \mathrm{~h}\left(60^{\circ} \mathrm{C}\right)$. Subsequently, $\mathrm{BiOCl}(0.5 \mathrm{~g})$ was added in sodium alginate aqueous solution $(30 \mathrm{~mL}, 0.0016 \mathrm{~g} / \mathrm{mL}$ ) and stirred continuously for $1 \mathrm{~h}$ to obtain a homogeneous alginate aqueous solution. Then, the mixture $(0.2 \mathrm{~mL})$ was injected into the conductive fluorine-doped tin oxide (FTO) substrate. The BiOCl hydrogel film electrode was obtained after immersing the coated FTO substrates into calcium chloride aqueous solution $(40 \mathrm{~mL}, 0.05 \mathrm{~g} / \mathrm{mL}$ ) for 30 $\min$. 


\section{Materials Characterization}

The XRD patterns of the as-prepared samples were conducted on a Bruker AXS D8 advanced automated diffractometer with $\mathrm{Cu} \mathrm{K} \alpha$ radiation $(\lambda=1.54060 \AA)$. X-ray photoelectron spectroscopy (XPS) was obtained using a monochromator X-rays (Quantum 2000, USA) with Al Ka radiation. The sample's morphology was observed by using a scanning electron microscope (SEM, Hitachi SU8010) and transmission electron microscopy (TEM, JEM-2100) were obtained on an apparatus. Energy-dispersive X-ray spectroscopy (EDS) and elemental mapping were acquired on the SEM (Oxford Instruments). UV-vis spectroscopy and diffuse reflectance spectroscopy (DRS) were tested on an UV-vis spectrometer (Shimadzu UV-2600) by using the semiconductor films.

\section{Electrochemical characterization}

The flat band (FB) potentials of $\mathrm{BiOCl}$ were determined from the Mott-Schottky (MS) plots recorded by electrochemistry workstation (CHI660E, Shanghai), where the sample acted as a working electrode, $\mathrm{Ag} / \mathrm{AgCl}$ electrode and $\mathrm{Pt}$ wire electrode acted as the reference electrode and counter electrode, respectively. The OER potential was investigated in a threeelectrode system in $0.5 \mathrm{M} \mathrm{KOH}$ aqueous electrolyte. The $\mathrm{BiOCl}$ hydrogel film electrode was used as a working electrode, the $\mathrm{Pt}$ wire and $\mathrm{Ag} / \mathrm{AgCl}$ electrode were used as the counter and reference electrodes, respectively. The ORR potential was also tested in a three-electrode system in $0.5 \mathrm{M} \mathrm{KOH}$ aqueous electrolyte with dual Pt electrodes, and $\mathrm{Ag} / \mathrm{AgCl}$ electrode were used as the reference electrodes. The redox potentials of elemental $\mathrm{Bi}$ in illuminated$\mathrm{BiOCl}$ hydrogel film electrode were investigated in a three-electrode system in $0.5 \mathrm{M} \mathrm{KOH}$ aqueous electrolyte. The illuminated-BiOCl hydrogel film electrode was used as a working electrode, the $\mathrm{Pt}$ wire and $\mathrm{Ag} / \mathrm{AgCl}$ electrode were used as the counter and reference electrodes, respectively. The current density-voltage (I-V) curves, photocurrent density-time (I-t), open-circuit voltage curves, cycling discharge curves and constant current chargingdischarging were tested in a two-electrode system including the BiOCl hydrogel film 
electrode as the working electrode, the $\mathrm{Pt} / \mathrm{O}_{2}$ as the counter electrode and $0.5 \mathrm{M} \mathrm{KOH}$ aqueous solution as the electrolyte. A BiOCl hydrogel film on the FTO substrate, a piece of $10 \mu \mathrm{m}$-thick mica and a platinum wire gauze electrode were assembled to make up the sample-chamber-like parallel-plate capacitor. A laser pulse $\left(355 \mathrm{~nm}, 50 \mathrm{~mJ} \cdot \mathrm{cm}^{-2}\right)$ with a width of $10 \mathrm{~ns}$ was used to excite the sample, and the photovoltaic signal was recorded over $100 \mathrm{~ns}$ to $10 \mathrm{~ms}$.

The Cullen number $(\mathrm{C})$ is calculated according to the Eq. S1 below:

$$
C=\int_{t_{0}}^{t_{d}} f(I \times V) d t_{d}
$$

Where $\mathrm{C}$ is the Cullen number, $V, I, t_{d}, t_{0}$ are open circuit voltage, short circuit current, discharge time and initial discharge time, respectively.

The theoretical capacity $\left(\mathrm{mAh} \cdot \mathrm{g}^{-1}\right)$ of the Solar-Metal-Air is calculated according to the Eq. S2 below:

$$
\begin{gathered}
\text { Theoretical Capacity }=\frac{\frac{1 g}{M_{B i}} \times F \times 3}{1 m A h} \\
1 \mathrm{mAh}=3.6 \mathrm{C}
\end{gathered}
$$

Here, $M_{B i}$ is the molecular mass of elemental $\mathrm{Bi}, F$ is the Faraday constant $\left(96485 \mathrm{C} \cdot \mathrm{mol}^{-}\right.$ $1)$. 
a

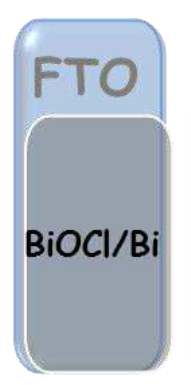

b

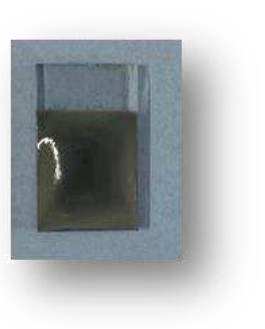

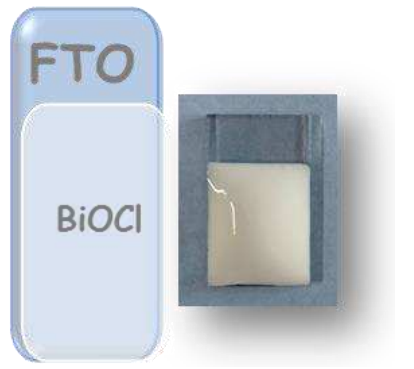

Figure S1. Photographs of the electrodes after (a) charging and (b) discharging process in SMABs.

Figure S1a shows the BiOCl/Bi hydrogel film electrode in the Solar-Metal-Air battery, it can be clearly seen that the electrode is black in the process of discharging, which is prepared by $\mathrm{BiOCl}$ hydrogel film electrode in solar-light-illumination (15 min or more), furthermore, with the discharging time goes on, the $\mathrm{BiOCl} / \mathrm{Bi}$ film electrode will gradually become white. The BiOCl hydrogel film electrode is illustrated in Figure S1b, initially, the BiOCl film electrode is white, as the light time increases, and the color of the film electrode gradually turns black. 
a

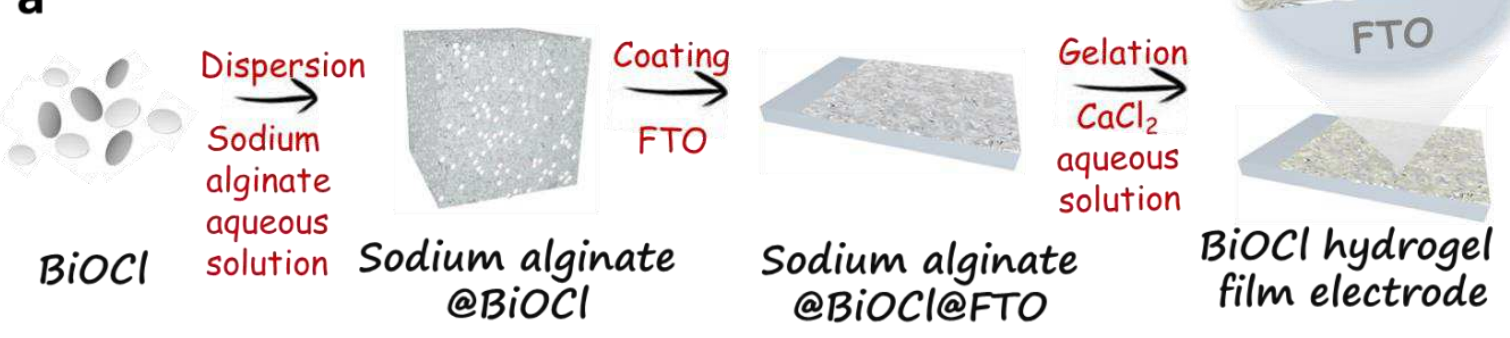

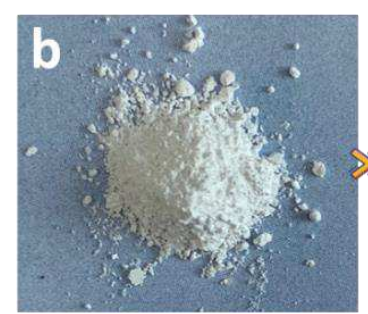

pure $\mathrm{BiOCl}$

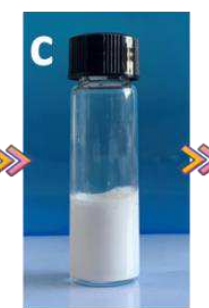

SA@BiOCI

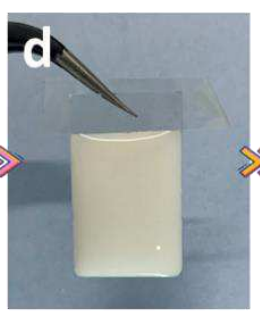

SA@BiOClC oating on FTO

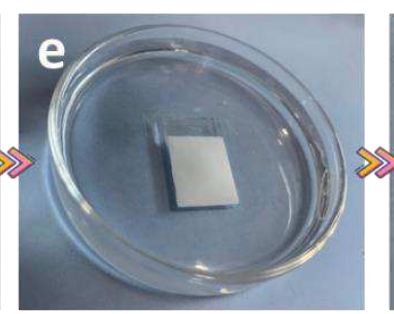

gelation of CA@BiOCl

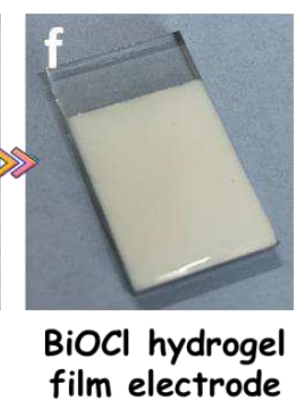

Figure S2. (a) Schematic illustration of the synthesis process of BiOCl hydrogel film electrode and photographs of the preparation process: (b) $\mathrm{BiOCl}$ powder; (c) the mixture of sodium alginate@ $\mathrm{BiOCl}$ in a vial; (d) the FTO with sodium alginate@ $\mathrm{BiOCl}$ coatings; (e) the gelation process of calcium alginate@ $\mathrm{BiOCl}$; (f) the $\mathrm{BiOCl}$ hydrogel film electrode.

$\mathrm{BiOCl}$ particles and sodium alginate are dispersed in water together, and the mixture of sodium alginate@BiOCl was extruded from a syringe onto the conductive fluorine-doped tin oxide (FTO) substrate. Then the sodium alginate@BiOCl coated FTO substrate was immersed in a calcium chloride aqueous solution (30 $\mathrm{min}$ or more) to form the calcium alginate@ BiOCl hydrogel film electrode (i.e. BiOCl hydrogel film electrode). 


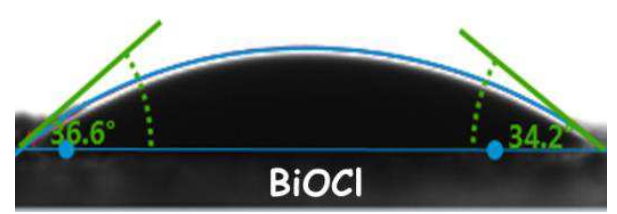

Figure S3. Contact angle of $\mathrm{BiOCl}$ powder.

As shown in Figure S3, the contact angle of $\mathrm{BiOCl}$ powder is $34.2 \sim 36.6^{\circ}$, suggesting that $\mathrm{BiOCl}$ is hydrophilic and easy to dissolve in water or water solution. 


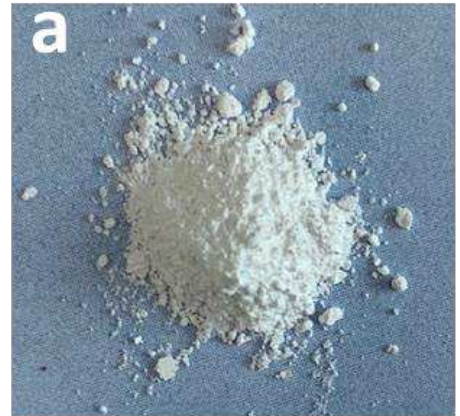

BiOCl powder

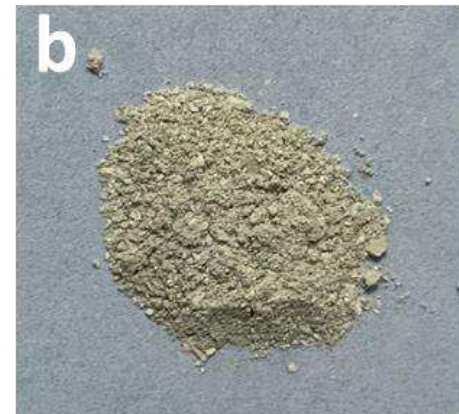

BiOCl powder after $15 \mathrm{~min}$ illumination

Figure S4. Photograph of (a) BiOCl powder and (b) BiOCl-15 min powder. 

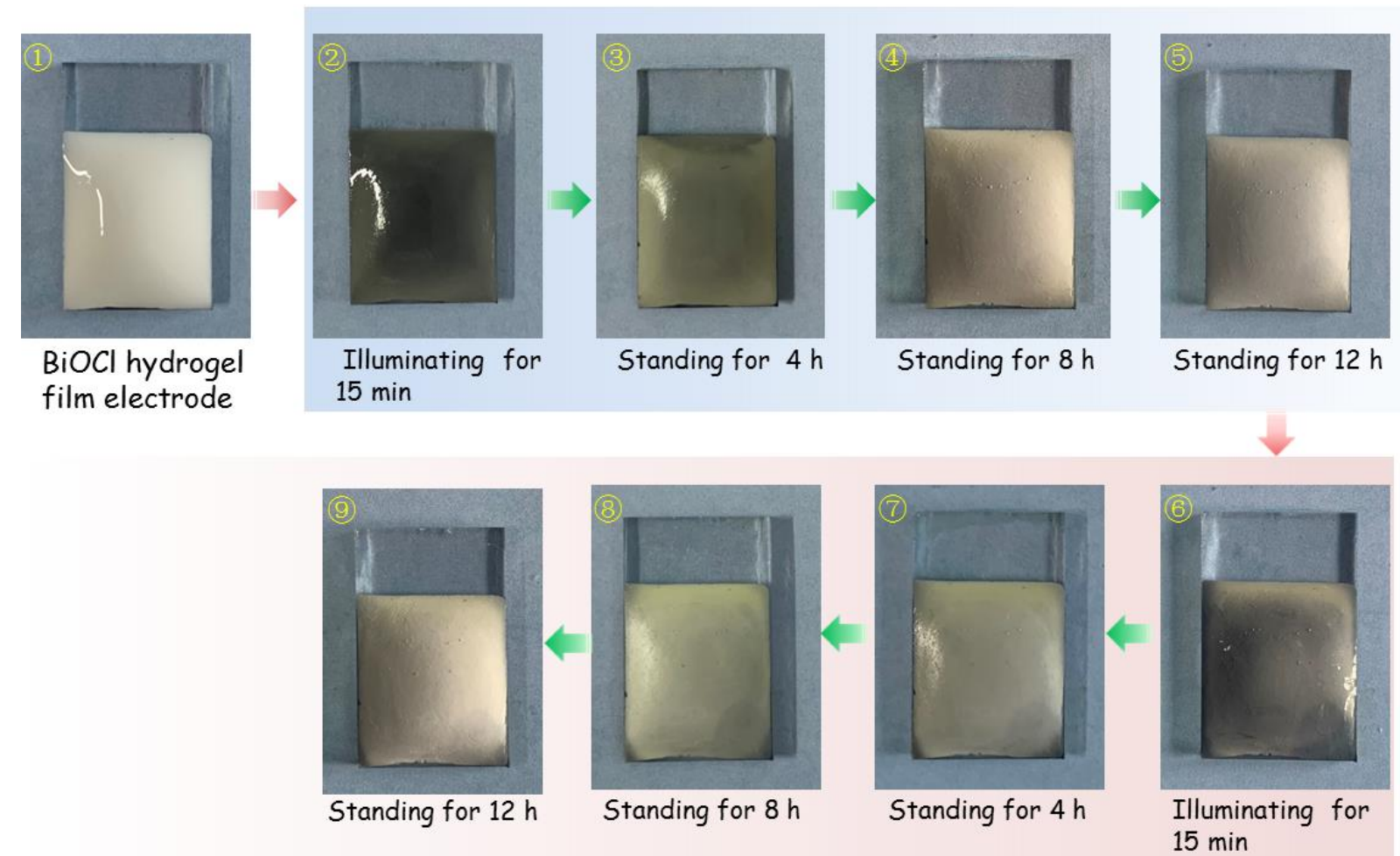

Figure S5. Photograph of the BiOCl hydrogel film electrode during the self-photocorrosion process.

The self-corrosion (self-redox) processes are shown in Figure S5, in two cycles, the BiOCl-15 min film electrode becomes light in color after standing $4 \mathrm{~h}$, and it turns completely white after standing $12 \mathrm{~h}$, these results prove that the self-corrosion (self-redox) processes are cyclic. 


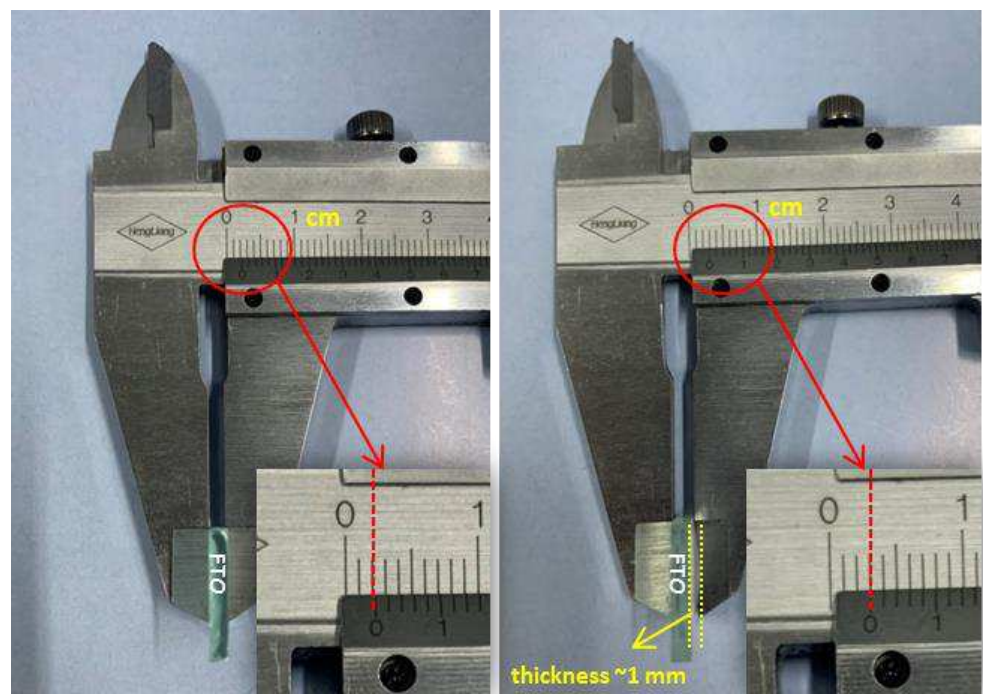

Figure S6. Photograph of the thickness of $\mathrm{BiOCl}$ hydrogel film electrode. 

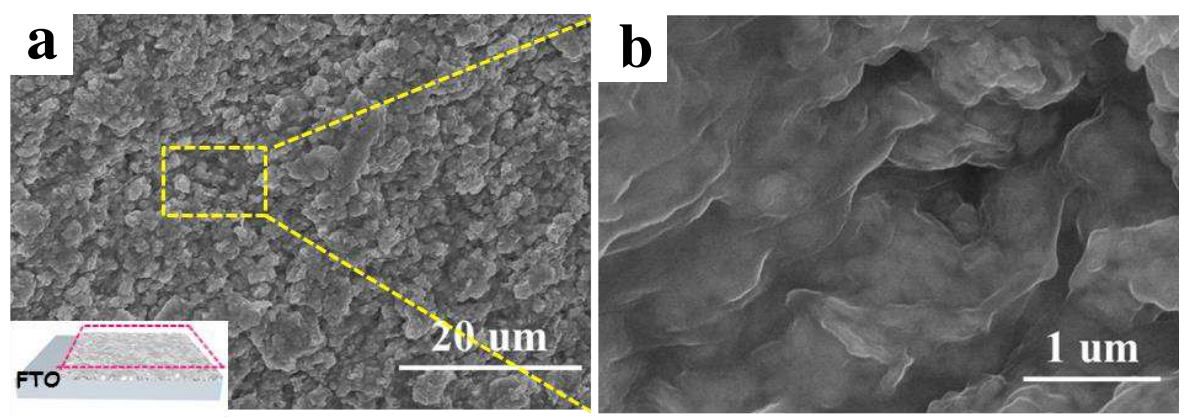

Figure S7. SEM images of surface morphology of the BiOCl hydrogel film electrode with different magnification.

As shown in Figure S7a, the surface of the BiOCl hydrogel electrode film exhibits a rough geometric squares structure. Moreover, the $\mathrm{BiOCl}$ particles on the surface are covered by calcium alginate hydrogel (Figure S7b). 

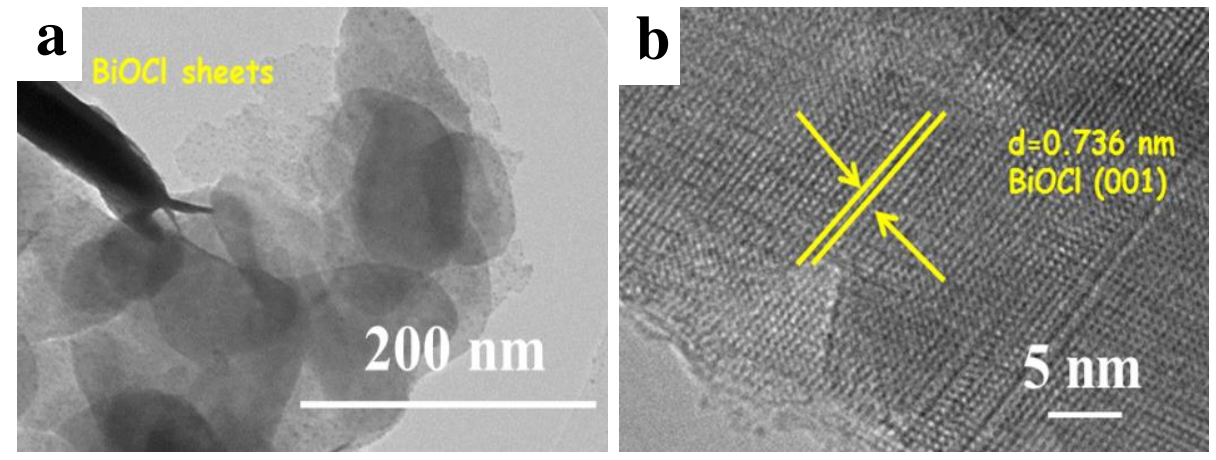

Figure S8. TEM images of $\mathrm{BiOCl}$ with different magnification.

Figure S8a shows the TEM image of the $\mathrm{BiOCl}$, and it can be clearly seen that the $\mathrm{BiOCl}$ with disc-shape structures exhibits a diameter of $\sim 100-200 \mathrm{~nm}$. Figure S8b shows the HRTEM image of the $\mathrm{BiOCl}$, with a lattice spacing $(0.736 \mathrm{~nm})$ can be observed, which corresponding to the (001) crystal plane of $\mathrm{BiOCl}$. 


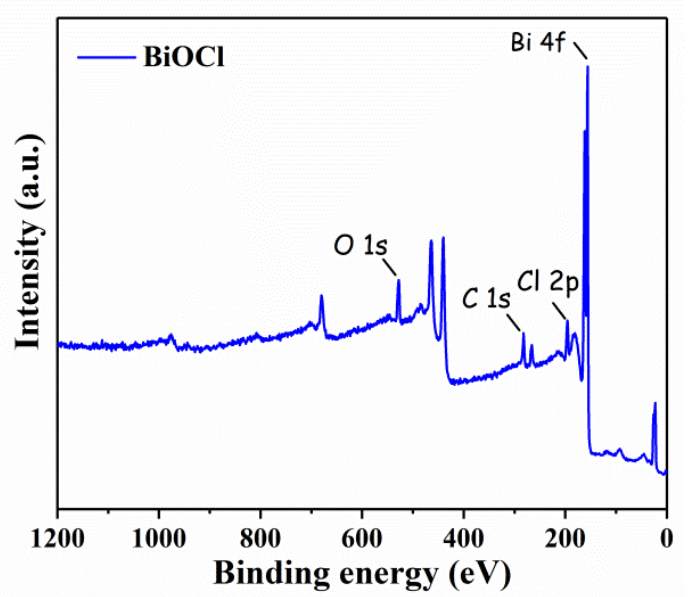

Figure S9. XPS survey spectra of BiOCl.

Figure $\mathrm{S} 9$ shows that $\mathrm{BiOCl}$ contains $\mathrm{Bi}, \mathrm{O}, \mathrm{C}$ and $\mathrm{Cl}$ elements. Among them, $\mathrm{C}$ 1s is chosen as the reference line. ${ }^{[3]}$ 


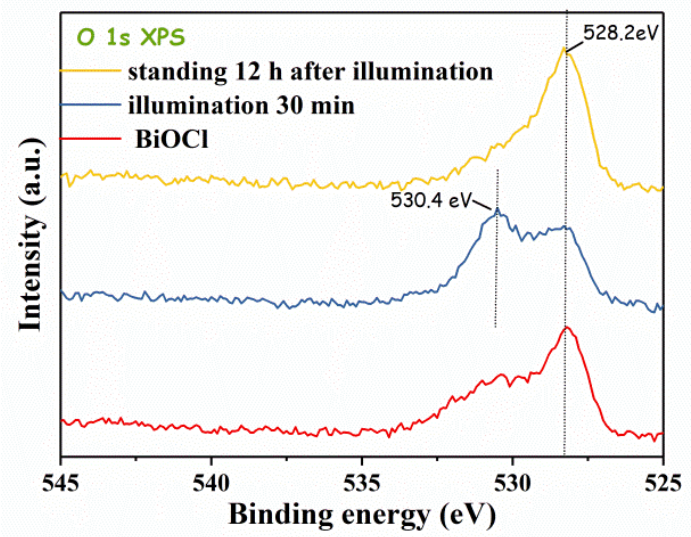

Figure S10. XPS O 1s spectra of the BiOCl-30 min powder.

Figure $\mathrm{S} 10$ shows the $\mathrm{O} 1 \mathrm{~s}$ spectrum of the BiOCl-30 min powder, which can be fitted with two main peaks at binding energies of $\sim 528.2 \mathrm{eV}$ and $\sim 530.4$ for the $\mathrm{O}^{2-}$ and $\mathrm{O}_{2}{ }^{2-}$ ions, respectively. ${ }^{[4]}$ 


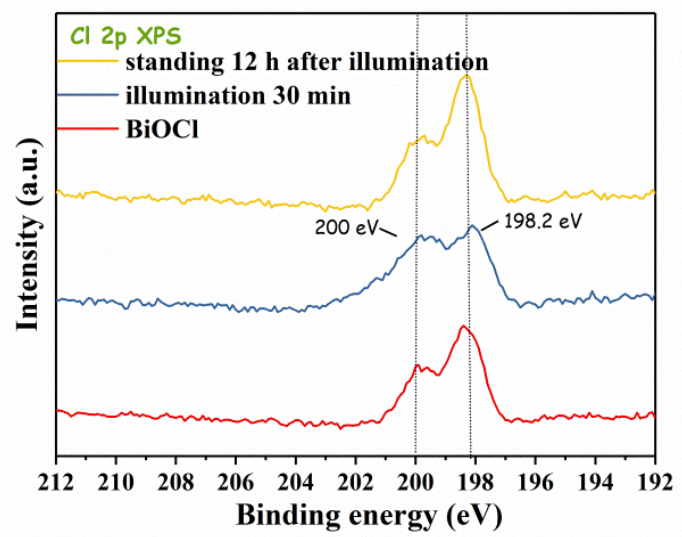

Figure S11. XPS Cl 2p spectra of the BiOCl-30 min powder.

In Figure S11, two dominant peaks located at $198.2 \mathrm{eV}$ and $200 \mathrm{eV}$ can be assigned to $\mathrm{Cl}$ $2 \mathrm{p}_{3 / 2}$ and $\mathrm{Cl} 2 \mathrm{p}_{1 / 2}$, respectively, which are all correspond to the $\mathrm{Cl}^{-}{ }^{[3]}$ 


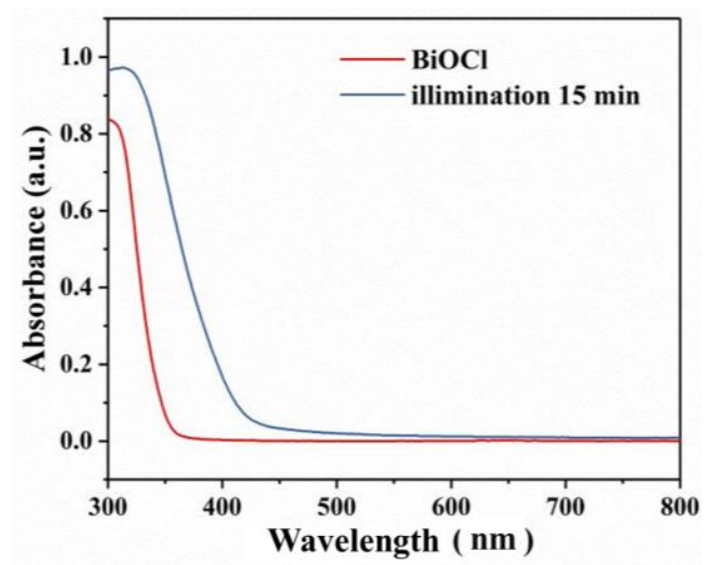

Figure S12.UV-vis absorption spectra of $\mathrm{BiOCl}$ powder and $\mathrm{BiOCl}-15$ min powder.

Figure S12 shows the UV-vis absorption spectra of $\mathrm{BiOCl}$ and $\mathrm{BiOCl}$ after $15 \mathrm{~min}$ illumination. It can be clearly observed that the $\mathrm{BiOCl}$ present an absorption edge at about $370 \mathrm{~nm}$, indicating that $\mathrm{BiOCl}$ mainly absorb UV light. Compared with $\mathrm{BiOCl}$, the absorption region of the $\mathrm{BiOCl}-15$ min powder (i.e. $\mathrm{BiOCl} / \mathrm{Bi}$ ) was broadened to $\sim 600 \mathrm{~nm}$. It proves the existence of $\mathrm{Bi}$, and $\mathrm{Bi}$ contributes to improving the utilization ratio of light. 


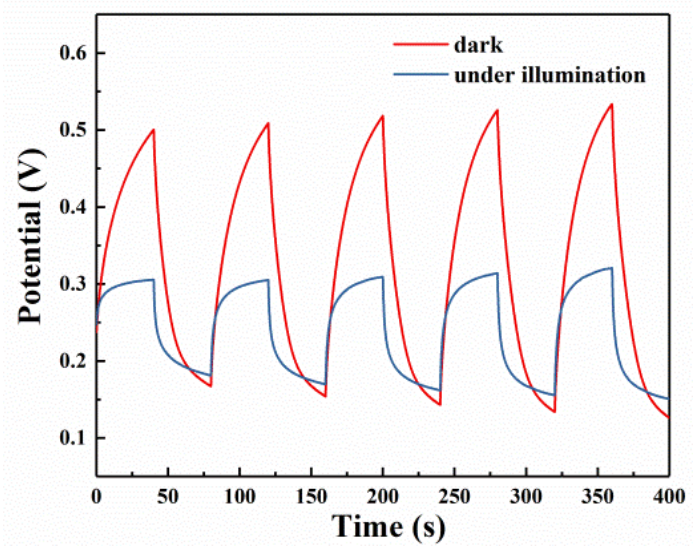

Figure S13. Cycling performance of the SMABs in the dark and under illumination at current density of $0.01 \mathrm{~mA} \cdot \mathrm{cm}^{-2}$.

The charge-discharge curves of the SMABs before and after illumination are shown in Figure S13, which further confirm that the light-charging reduces the charging voltage of the SMABs. 


\section{References}

[1] Y. Myung, F. Wu, S. Banerjee, J. Park, P. Banerjee, Chem. Commun. 2015, 51, 2629.

[2] K. Liu, H. J. Ding, J. Liu, Y.Chen, X. Z. Zhao, Langmuir 2006, 22, 9453.

[3] H. Wang, W. D. Zhang, X. W. Li, J. Y. Li, W. L. Cen, Q. Y. Li, F. Dong, Appl. Catal. BEnviron. 2018, 225, 218.

[4] J. Hrbek, Y. W. Yang, J. A. Rodriguez, Surf. Sci. 1993, 296, 164. 